\title{
Layer 4 in Primary Visual Cortex of the Awake Rabbit: Contrasting Properties of Simple Cells and Putative Feedforward Inhibitory Interneurons
}

\author{
Jun Zhuang (庄骏), ${ }^{1}$ Carl R. Stoelzel, ${ }^{1}$ Yulia Bereshpolova, ${ }^{1}$ Joseph M. Huff, ${ }^{1}$ Xiaojuan Hei (黑晓娟), ${ }^{1}$ \\ Jose-Manuel Alonso, ${ }^{2,1}$ and Harvey A. Swadlow ${ }^{1,2}$ \\ ${ }^{1}$ Department of Psychology, University of Connecticut, Storrs, Connecticut 06269, and 2Department of Biological Sciences, State University of New York, \\ New York, New York 10036
}

Extracellular recordings were obtained from two cell classes in layer 4 of the awake rabbit primary visual cortex (V1): putative inhibitory interneurons [suspected inhibitory interneurons (SINs)] and putative excitatory cells with simple receptive fields. SINs were identified solely by their characteristic response to electrical stimulation of the lateral geniculate nucleus (LGN, $3+$ spikes at $>600 \mathrm{~Hz}$ ), and simple cells were identified solely by receptive field structure, requiring spatially separate $\mathrm{ON}$ and/or OFF subfields. Notably, no cells met both criteria, and we studied 62 simple cells and 33 SINs. Fourteen cells met neither criterion. These layer 4 populations were markedly distinct. Thus, SINs were far less linear (F1/F0 $<1)$, more broadly tuned to stimulus orientation, direction, spatial and temporal frequency, more sensitive to contrast, had much higher spontaneous and stimulus-driven activity, and always had spatially overlapping ON/OFF receptive subfields. SINs responded to drifting gratings with increased firing rates (F0) for all orientations and directions. However, some SINs showed a weaker modulated (F1) response sharply tuned to orientation and/or direction. SINs responded at shorter latencies than simple cells to stationary stimuli, and the responses of both populations could be sustained or transient. Transient simple cells were more sensitive to contrast than sustained simple cells and their visual responses were more frequently suppressed by high contrasts. Finally, cross-correlation between LGN and SIN spike trains confirmed a fast and precisely timed monosynaptic connectivity, supporting the notion that SINs are well suited to provide a fast feedforward inhibition onto targeted cortical populations.

\section{Introduction}

The cerebral cortex is organized in six layers that can be distinguished based on cell morphology, functional connections, and response properties. Among all layers, layer 4 has been studied more intensively because it is the layer that receives the bulk of the thalamic inputs and provides the main entrance of sensory information to the cortex. In primary visual cortex (V1), layer 4 circuits are involved in generating neuronal response properties such as orientation and direction selectivity that are essential for visual processing. While these properties are thought to emerge from the interplay between excitation and inhibition, we still do not have a complete understanding of how inhibitory and excitatory neurons of this layer differ in their responses to visual stimuli. Moreover, a full understand-

\footnotetext{
Received Feb. 25, 2013; revised May 10, 2013; accepted May 19, 2013.

Author contributions: J.Z., C.R.S., Y.B., J.-M.A., and H.A.S. designed research; J.Z., C.R.S., Y.B., J.M.H., and X.H. performed research; J.Z., C.R.S., Y.B., J.-M.A., and H.A.S. contributed unpublished reagents/analytic tools; J.Z., C.R.S., Y.B., J.M.H., X.H., J.-M.A., and H.A.S. analyzed data; J.Z., J.-M.A., and H.A.S. wrote the paper.

This work was supported by National Institutes of Health Grant EY018251. We thank Victor Serdyukov for superb software development and hardware support.

The authors declare no competing financial interests.

Correspondence should be addressed to Harvey A. Swadlow, Department of Psychology (U-1020), The University of Connecticut, 406 Babbidge Road, U-1020, Storrs, Connecticut 06269. E-mail: harvey.swadlow@uconn.edu.

DOI:10.1523/JNEUROSCI.0863-13.2013

Copyright $\odot 2013$ the authors $\quad 0270-6474 / 13 / 3311372-18 \$ 15.00 / 0$
}

ing of neuronal mechanisms involved in visual perception requires the study of subjects that are awake and capable of perception. To these ends, we have investigated the response properties of layer 4 putative excitatory and inhibitory neurons [suspected inhibitory interneurons (SINs)] in awake rabbits. Both rabbits and rodents are closely related to primates [superorder of Euarchontoglires, also known as supraprimates (Murphy et al., 2001; Asher et al., 2009)] but, unlike primates, the rabbit eye remains nearly motionless for considerable periods of time, making quantitative receptive field (RF) analyses feasible in awake subjects (Bezdudnaya et al., 2006; Cano et al., 2006).

We have previously shown that the great majority of neurons in lateral geniculate nucleus (LGN) of awake rabbits have concentric RFs that are bimodally distributed into sustained and transient classes (Swadlow and Weyand, 1985; Bezdudnaya et al., 2006; Cano et al., 2006). We also demonstrated that transient and sustained concentric LGN neurons differ in their contrast sensitivity (Cano et al., 2006), temporal tuning properties (Bezdudnaya et al., 2006), and project to different depths within cortical layer 4 (Stoelzel et al., 2008). Here, we move this investigation to primary visual cortex and compare the response properties of layer 4 simple cells and SINs. We show that these populations differ dramatically along multiple RF property dimensions. Thus, when compared with sim- 
ple cells, SINs are very broadly tuned to stimulus orientation, direction, temporal frequency, and spatial frequency, and they respond in a much more nonlinear manner (low F1/F0 ratios), and at higher firing rates to drifting grating stimulation. We also show that, like LGN cells, simple cells and SINs can be subdivided into sustained and transient subclasses that differ significantly in their contrast sensitivity. We finally show, using cross-correlation methods, that many layer 4 SINs do, indeed, receive direct input from retinotopically aligned LGN neurons [i.e., that these putative inhibitory interneurons receive a potent feedforward thalamic input (Swadlow, 2003; Gabernet et al., 2005; Cruikshank et al., 2007)] and, as such, are optimally positioned to shape the response properties of layer 4 simple cells (Hirsch et al., 1998; Troyer et al., 1998; Miller et al., 2001; Liu et al., 2011).

\section{Materials and Methods}

Recordings were obtained from monocular V1 of three awake adult female Dutch-Belted rabbits. All experiments were conducted with the approval of the University of Connecticut Animal Care and Use Committee in accordance with National Institutes of Health guidelines.

Animal preparation and electrophysiological recording. The general surgical procedures for chronic recordings have been described previously (Bezdudnaya et al., 2006; Stoelzel et al., 2008; Bereshpolova et al., 2011) and are reported only briefly here. Initial surgery was performed under ketamine-acepromazyne anesthesia using aseptic procedures. After removal of the skin and fascia, stainless steel screws were installed on the dorsal surface of the skull and fused together with acrylic cement. A stainless steel rod, oriented in a rostrocaudal direction, was then cemented to the acrylic mass. The rabbit was held rigidly by this rod during the electrode implantation and recording sessions. Silicone rubber was used to buffer the wound margins from the acrylic cement on the skull. Following at least $10 \mathrm{~d}$ of recovery, recordings of neuronal activity were obtained in the awake state through a small hole in the skull.

Extracellular single-unit recordings and cortical local field potentials (LFP) were obtained from the monocular region of $\mathrm{V} 1$ of awake rabbits. Single unit activity for most cells was studied using fine-diameter (40 $\mu \mathrm{m})$ quartz-insulated platinum/tungsten electrodes tapered and sharpened to a fine tip (impedance, 1.5-3 Mohm). A group of seven such electrodes was chronically implanted in a concentric array $(200 \mu \mathrm{m}$ separation), with tips initially located just above the dura. Each of these electrodes was independently controlled by a miniature microdrive (Swadlow et al., 2005). Multiunit activity from superficial layers of the superior colliculus (SC) was simultaneously recorded via 1-3 electrodes of same type but lower impedance $(<1.5 \mathrm{Mohm})$ controlled by a similar three-channel microdrive system. A small number of cells were studied using 16-channel silicone probes, with recording site diameters of $33 \mu \mathrm{m}$ (NeuroNexus Technologies). Two stimulating electrodes (parylene-cinsulated platinum/iridium microwire) were implanted in LGN for identification of cortical neurons (below). Hippocampal EEG was recorded using two electrodes implanted above and below the CA1 layer and used, along with cortical EEG, for monitoring brain states. All electrophysiological activity was acquired using a Plexon data acquisition system.

In another set of experiments, SINs in V1 layer 4 were recorded simultaneously with LGN cells from topographically aligned regions of dorsal LGN as described in our earlier studies (Swadlow and Gusev, 2002; Stoelzel et al., 2009; Bereshpolova et al., 2011). In this set of experiments, only spontaneous activity and response to sparse noise (see below) of both LGN cells and cortical SINs were recorded.

Brain state identification. During recordings, no anesthetic agents were applied, the eyes were open, and subjects responded to external stimuli (novel sound and gentle touch, etc.). Our goal was to record when subjects were awake, either alert or nonalert, in approximately equal proportions. In rabbits, wakefulness can be divided into alert and nonalert states. The alert state is indicated by hippocampal "theta" activity (5-7 $\mathrm{Hz}$ ) and cortical desynchrony, and the nonalert state is indicated by hippocampal high-voltage irregular activity, and more slow-wave activity in the neocortex (Swadlow and Gusev, 2001; Bezdudnaya et al., 2006; Cano et al., 2006; Stoelzel et al., 2008; Stoelzel et al., 2009; see recent discussion in Bereshpolova et al., 2011). The hippocampal EEG was segmented by visual inspection into alert versus nonalert states based on the presence of theta activity $(5-7 \mathrm{~Hz})$ or high-voltage, irregular activity, respectively (Swadlow and Gusev, 2001; Bezdudnaya et al., 2006; Cano et al., 2006; Stoelzel et al., 2009). This segmentation was aided and verified by fast Fourier transform (FFT) analysis. Some nonperiodic sensory stimulation (random sounds, tactile stimulation, movements in room) is often required to keep rabbits from transitioning from the awake, nonalert state to sleep (early signs of which are indicated by cortical spindle activity), and such stimulation was applied when needed. During recording sessions, the average percentages of time the animals spent in the alert state and nonalert state were $32.94 \pm 1.36 \%$ and $36.28 \pm 2.20 \%$, respectively. In some cases, when rabbits became drowsy during extended recordings, we provided novel sounds to generate alertness. If they were difficult to arouse, we let them sleep for a while, and did not collect data during these periods.

Cortical layer 4 identification. Depth range of cortical layers was determined by electrode depth and reversal of stimulus-evoked field potentials that occur at known depths. Brief full-field flash-evoked LFPs were recorded at different depth. As previously verified histologically (Stoelzel et al., 2008), the top of layer 4 was identified as $100 \mu \mathrm{m}$ below a prominent current sink/source reversal point to the flash stimuli and the bottom of layer 4 was identified as $400 \mu \mathrm{m}$ below the top of this layer. Only neurons within this narrow $(400 \mu \mathrm{m})$ depth zone were included in this study.

Identification of SINs and simple cells. For each cell, the response to electrical stimulation of the thalamus (rectangular voltage pulses, $0.2 \mathrm{~ms}$ duration, range: $<1-45 \mathrm{~V}$ ) was recorded (latency of first spike, spike number after stimulation, and minimal interspike interval of these spikes; Fig. 1A). SINs were identified by a high-frequency discharge of three or more spikes to this stimulus, with peak frequencies of $>600 \mathrm{~Hz}$ (Swadlow, 1988, 1989, 1991, 1995, 2003). Cells identified in this manner have spikes of short duration (see below). However, many cortical projection neurons also have short duration spikes (Swadlow, 1988, 1990, 1991, 1994) and we have, therefore, argued that spike duration is not a sufficient criterion for identifying SINs (Swadlow, 2003). Cortical simple cells were identified by possessing a RF with one, two, or three spatially separated ON and/or OFF subfields. Cells that could not be classified as simple cells or SINs were grouped as "other cells" and were not subject to further analysis. Two cells that were antidromically activated by thalamic stimulation were thought to be dendritic recordings (Bereshpolova et al., 2007) and were excluded from this study.

Receptive field and visual response property measurements. All visual stimuli for cortical cells were presented by a CRT monitor (primary monitor, Nec MultiSync, $40 \times 30 \mathrm{~cm}$, mean luminance, $48 \mathrm{~cd} / \mathrm{m}^{2}$, refresh rate: $160 \mathrm{~Hz}$ ). The cells' RFs were mapped by sparse noise stimulation. High-contrast light and dark squares $(1 \times 1$ to $5 \times 5$ degrees, mostly $2 \times$ 2 degrees) were presented pseudorandomly, in a grid of $30 \times 22$ degrees on the primary monitor. Each grid space was 1 degree and each square was presented for either 18.75 or $31.25 \mathrm{~ms}$. For some layer 4 simple cells that responded poorly to flashing squares, small flashing bars in their preferred orientation were used instead to map their RFs. The cell's raw $\mathrm{ON}$ and OFF RF matrices were generated by reverse correlation method (Jones and Palmer, 1987; Stoelzel et al., 2008) (see below). After mapping, the cell's RF center was constantly tracked by dynamic SC multiunit RF position, and all the visual stimuli thereafter were presented to the cell's RF center (see below).

In the rabbit LGN, the response of concentric neurons to stationary stimuli can be classified as either "sustained" or "transient," and this distinction is robust and bimodal (Bezdudnaya et al., 2006). However, the sustained response is severely attenuated when animals are not alert in both LGN (Swadlow and Weyand, 1985) and V1 (Swadlow and Weyand, 1987). Therefore, we classified cortical neurons as sustained or transient based on tests that were done in the alert state. The cell's sustained/ transient property was measured with flashing stationary stimuli, which were optimized to elicit the strongest response possible. The stimulus was 
either a circle or rectangle optimized for size, orientation, and contrast polarity (dark or light). The stimulus was presented either $1 \mathrm{~s}$ on and $1 \mathrm{~s}$ off or $2 \mathrm{~s}$ on $2 \mathrm{~s}$ off (see below).

After assessing sustained/transient responses, circular drifting gratings were used to measure the tuning properties of the cell. The drifting grating was optimized by orientation, spatial frequency, temporal frequency, size, and contrast. After optimizing the grating, the cell's tuning properties were measured by pseudorandomly varying one of the four (orientation, spatial frequency, temporal frequency, or contrast) grating parameters while keeping the other four at the optimal values. Each presentation of a particular parameter combination lasted for 3-8 $\mathrm{s}$ with a $2 \mathrm{~s}$ gap in between and all tested parameter combinations were presented for at least 100 times. For some cells, the spontaneous activity was also recorded for at least $10 \mathrm{~min}$ with the monitor screen set at a mid-luminance level.

Monitoring eye position. The eye position of the awake rabbit is generally very stable (Collewijn, 1971; Fuller, 1981; Swadlow and Weyand, 1985, 1987; Bezdudnaya et al., 2006). During recording sessions, the eye position was continuously monitored by mapping the SC multiunit RF center position with sparse noise on a second LCD monitor (Acer AL1516, $30 \times$ $23 \mathrm{~cm}$, mean luminance, $36 \mathrm{~cd} / \mathrm{m}^{2}$, refresh rate, $75 \mathrm{~Hz}$ ). For most cells, the pupil position and size were also simultaneously monitored by a high-frequency $(220 \mathrm{~Hz})$ infrared camera system (ViewPoint EyeTracker system, Arrington Research) placed $\sim 40 \mathrm{~cm}$ from the eye. If an eye movement occurred during testing, the relation between the RF centers of the cortical cell and SC multiunit $\mathrm{RF}$ center was used to dynamically place the stimuli on the cortical RF center. During the offline analysis, we discarded data recorded within $\pm 15 \mathrm{~s}$ around the eye movement by sliding a time window of $25-30 \mathrm{~s}$ with a step of $5 \mathrm{~s}$ over time and detecting the steps in which the SD of SC RF centers was $>1$ degree. Visual responses to drifting gratings were measured by generating peristimulus time histograms (PSTHs) during stable eye periods, and the PSTH peaks at the fundamental frequency were aligned across these periods. Only the cells with significant responses at the fundamental frequency were processed with this alignment method.

Offline data analysis. Spikes from cortical single units were isolated during the experiment and verified off-line by using Plexon cluster analysis software. All data analysis was then performed with NeuroExplorer (Nex Technologies) and MATLAB (The MathWorks).

Spike waveform. Spike waveform durations were calculated as the durations from the beginning of negative component to the end of positive component of the spike (Bereshpolova et al., 2011). The negative or positive components were identified by lower or higher than $20 \%$ of negative or positive peak amplitudes, respectively. If the end part of the spike waveform did not reach the $20 \%$ threshold, the whole waveform was estimated by elongating the raw waveform through a linear fitting of the end part (from the peak of positive component to the end). Then the spike durations were calculated from the elongated waveforms.

Spatial properties of ON-OFF RF subfields. For each cell, the raw ON and OFF RF matrices were calculated by spike-trigger averaging the stimulus within a $20 \mathrm{~ms}$ time window around the peak response. A Gaussian filter was applied to smooth these matrices. Finally, the processed ON and OFF RF maps were generated by applying a threshold as $30 \%$ of maximum pixel value.

To measure the spatial segregation of subfields, the local similarity index (LSI) was calculated as normalized dot product of the processed ON and
B

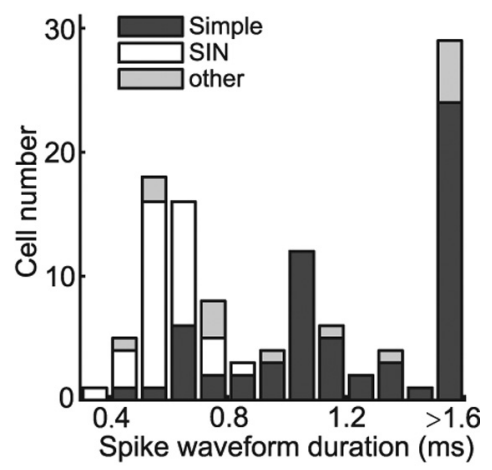

D

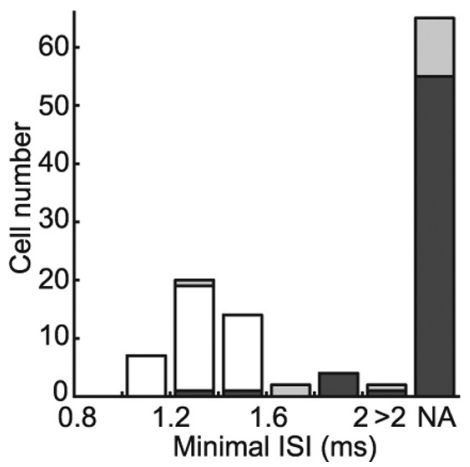

Responses to thalamic electrical stimulation and spike waveform durations of different cell types. $\boldsymbol{A}$, Conceptual 作 nset of stimulation $(\boldsymbol{C})$, and minimal ISIs of responding spikes $(\boldsymbol{D})$ of different cell types. "NA" in $\boldsymbol{D}$ represents cells that responded to thalamic stimulation with $<2$ spikes.

OFF RF maps (DeAngelis et al., 1999; Usrey et al., 1999; Alonso et al., 2001), as follows:

$$
\mathrm{LSI}=\left(\mathrm{RF}_{\mathrm{ON}} \cdot \mathrm{RF}_{\mathrm{OFF}}\right) / \sqrt{\left(\mathrm{RF}_{\mathrm{ON}} \cdot \mathrm{RF}_{\mathrm{ON}}\right)\left(\mathrm{RF}_{\mathrm{OFF}} \cdot \mathrm{RF}_{\mathrm{OFF}}\right)} .
$$

The values of LSI range from 0 to 1 . LSI equals 1 if the ON and OFF RF maps are identical and perfectly superimposed and equals 0 if the $\mathrm{ON}$ and OFF RF maps are completely separated.

Dominant RF subfield area and width were used to estimate the size of RF subfields. To get these measurements, processed ON and OFF RF maps went through cubical interpolation at resolution of 0.1 degree. Then RF subfield was defined by a region of contiguous pixels with values $>30 \%$ of maximum pixel (the higher value of ON peak and OFF peak). Finally, the dominant RF subfield was defined as the stronger subfield, ON or OFF. For each dominant subfield, the area and the width (on the orientation orthogonal to the cell's optimal orientation) were measured.

Sustained index and sustained/transient classification. In the alert state, a sustained index (SI) was calculated as the ratio between the cell's maintained response and the baseline activity. The maintained response was measured as the mean firing rate within $0.5-1.0 \mathrm{~s}$ after the onset of optimal stationary stimuli, and the baseline activity was measured as the mean firing rate within the time window of either -1 to 0 or -0.5 to $0 \mathrm{~s}$ relative to the onset of stimuli. Sustained cells were defined by having SIs $>2$ and having an absolute maintained response of $>1 \mathrm{spk} / \mathrm{s}$. Cells with SIs $<2$ were classified as transient. Cells that failed to reach these criteria ( $\mathrm{SI}>2$ but the absolute maintained activity $<1 \mathrm{spk} / \mathrm{s}$ ) remained as "sustained/transient unclassified."

Latency to flash stimulation. The latency to flash stimulation was measured from the cell's response to optimal flashing stimuli. The PSTH (with bin size equal to $1 \mathrm{~ms}$ ) around the onset of the stimuli was generated and smoothed by applying a sliding boxcar filter with width of 30 ms. Each stimulus frame was time-stamped, and, because stimuli presented higher in the field occur slightly sooner than those presented lower 
in the field, stimulus onset time was corrected for the position of the stimulus on the screen. Latency was defined as the time at which the smoothed function first pass $40 \%$ of its maximum value (Jin et al., 2011).

Drifting grating parameter tuning properties. The mean firing rate (F0) and first harmonic component (F1) of the PSTH responding to drifting grating stimuli were calculated by Fourier analysis. The maximum F1 and maximum F0 responses (with or without the spontaneous activity) were measured for each cell. Spatial summation linearity was measured as the mean of two F1/F0 ratios, one ratio measured from the PSTH with strongest F1 response and the other from the PSTH with strongest F0 response. Reliability was measured with an optimized grating stimulus as the Fano factor (variance/mean) with a bin size equal to the period of the stimulation. Almost all simple cells ( $>95 \%$; defined by segregated ON and OFF RF subfields) had stronger F1 than F0 responses and all SINs had stronger F0 than F1 responses (see Results). Therefore, the F1 response was used to measure tuning properties for simple cells and the F0 response to measure tuning properties for SINs (if not otherwise stated).

Contrast tuning responses were tested on eight different contrasts ranging from 1 to 95\% (Cano et al., 2006). Because some cells showed decreased responses at high contrast (high-contrast suppression, see Results), F1 and F0 responses were fitted by a hyperbolic model with (Peirce, 2007) or without (Naka and Rushton, 1966; Albrecht and Hamilton, 1982) high-contrast suppression modification, as follows: F0 response without high-contrast suppression: $y=R_{0}+A^{*} x^{n} /\left(C^{n}+x^{n}\right)$; F0 response with high-contrast suppression: $y=R_{0}+A^{*} x^{n} /\left(C^{s n}+x^{s n}\right)$; F1 response without high-contrast suppression: $y=A^{*} x^{n} /\left(C^{n}+x^{n}\right)$; F1 response with high-contrast suppression: $y=A^{\star} x^{n} /\left(C^{s n}+x^{s n}\right)$; where $A$ is the response amplitude, $R_{0}$ is baseline activity, $x$ is contrast, and $C$ is the contrast at half maximum response. The parameters $A$ and $C$ from the equations above are generally used to describe the response amplitude and the contrast generating the half-maximum response (C50), respectively (Albrecht and Hamilton, 1982; Cano et al., 2006). However, the parameters extracted from the fit do not faithfully represent the values of the contrast response function in the model with high-contrast suppression, which can span to contrast values larger than $100 \%$. Therefore, the response amplitude $\left(R_{\text {con }}\right)$ and the C50 were calculated by limiting the fitting function within a contrast ranging from 0 to $100 \%$. All contrast response functions were fitted with and without high-contrast suppression and the $R^{2}$ of fitness normalized by degree of freedom (df) was measured in both fits (Peirce, 2007): $R_{\text {nor }}^{2}=1-\left(1-R^{2}\right) / \mathrm{df}$. The model with higher $R_{\text {nor }}^{2}$ was chosen to extract the parameters $R_{\text {con }}$ and C50.

Orientation tuning was measured with drifting gratings differing in orientation/direction by 15-30 degrees. Tuning curves were fitted by von Mises distribution functions (Nowak et al., 2008), as follows:

$$
\begin{aligned}
y=R_{0} & +A_{1} \exp \left\{k\left[\cos \left(x-\mathrm{OR}_{\text {peak }}\right)-1\right]\right\} \\
& +A_{2} \exp \left\{k\left[\cos \left(x-\mathrm{OR}_{\text {peak }}+\pi\right)-1\right]\right\}, \text { where } A_{1} \geq \mathrm{A}_{2} .
\end{aligned}
$$

Here, the independent variable $x$ (the moving direction of the tested drifting grating) is presented in radians. From this model, $R_{0}$ represents the baseline of the curve, and $A_{1}$ and $A_{2}$ represent the response amplitude to the preferred direction (OR_peak) and to the opposite of preferred direction, respectively. $k$ is a width factor. To measure the orientation selectivity and direction selectivity, the circular variance (CirVar) (Ringach et al., 2002), orientation selectivity index (OSI), and direction selectivity index (DSI) were calculated as follows:

$$
\begin{aligned}
\text { CirVar } & =1-\left|\frac{\sum R_{\mathrm{j}} \mathrm{e}^{\mathrm{i} 2 \theta_{\mathrm{j}}}}{\sum R_{\mathrm{j}}}\right| ; \\
\text { OSI } & =\frac{\left(R_{\text {pref }}+R_{\text {orth }}\right)}{\left(R_{\text {pref }}+R_{\text {orth }}\right)} ; \\
\text { where } R_{\text {orth }} & =\frac{R_{\text {pref }}+\frac{\pi}{2}+R_{\text {pref }-\frac{\pi}{2}}}{2} ; \\
\text { DSI }= & \frac{\left(R_{\text {pref }}-R_{\text {oppo }}\right)}{\left(R_{\text {pref }}+R_{\text {oppo }}\right)} ;
\end{aligned}
$$

where $\mathrm{j}$ represents all the directions in the orientation tuning curve; $R_{\mathrm{j}}$ and $\theta_{j}$ represent the cells response (spk/s) and the angle (in radians) of $j$ th direction, respectively; $R_{\text {pref }}$ represents the cell's response in the preferred direction; $R_{\text {orth }}$ represents the cell's mean responses of the two directions orthogonal to the preferred direction; and $R_{\text {oppo }}$ represents the cell's response to the opposite of the preferred direction. All three measurements (CirVar, OSI, and DSI) have values ranging from $0-1$, with higher CirVar meaning weaker orientation selectivity; higher OSI meaning stronger orientation selectivity, and higher DSI meaning stronger direction selectivity.

Spatial frequency responses were tested from $0.00825-1.32 \mathrm{cpd}$ (for some cells from 0.05 to $1.32 \mathrm{cpd}$ ). The response tuning data were fitted by a Gaussian model, as follows:

$$
y=R_{0}+R_{\mathrm{SF}} \times \exp \left[-(x-\text { SF_peak })^{2} / 2 \sigma_{\mathrm{SF}}^{2}\right] .
$$

From the model, the amplitude $\left(R_{\mathrm{SF}}\right)$ and the spatial frequency with peak response (SF_peak) were extracted. Cells with response at lowest tested spatial frequency $>50 \%$ of peak response were defined as spatially low pass cells, otherwise as spatially bandpass cells. Spatial frequency tuning width for low-pass cells was defined by the range from lowest tested spatial frequency to the spatial frequency with half-maximum response on logarithmic scale (with base 10). Whereas tuning width for bandpass cells was measured as the range between two spatial frequencies with half-maximum response on logarithmic scale (SF_width) as follows:

SF_width $=\log _{10}\left[\left(\right.\right.$ SF_peak $\left.+1.17741 \times \sigma_{\mathrm{SF}}\right) /$

$$
\left.\left(\text { SF_peak }-1.17741 \times \sigma_{\mathrm{SF}}\right)\right] .
$$

Temporal frequency responses were tested on six different temporal frequencies $(0.5,1,2,4,8$, and $16 \mathrm{~Hz})$. The temporal frequency tuning curve was fitted by Gaussian model on logarithmic scale [with base 2, modified from the study by Bezdudnaya et al. 2006)].

$$
y=R_{0}+R_{\mathrm{TF}} \times \exp \left\{-\left[\log _{2}(x)-\log _{2}\left(\mathrm{TF} \_ \text {peak }\right)\right]^{2} / 2 \sigma_{\mathrm{TF}}^{2}\right\} .
$$

From the model, the amplitude $\left(R_{\mathrm{TF}}\right)$ and the temporal frequency with peak response (TF_peak) were extracted. Temporal frequency tuning width was measured as the width at half-height on logarithmic scale (TF_width, with base 2), as follows: $\mathrm{TF} \_$width $=2.35482{ }^{*} \sigma_{\mathrm{TF}}$.

Goodness of fitting showed the models used here faithfully described the tuning properties of the cells' responses $\left(R^{2}\right.$, contrast tuning: $0.972 \pm$ $0.007, n=65$; temporal frequency tuning: $0.925 \pm 0.010, n=78$; spatial frequency tuning: $0.919 \pm 0.010, n=72$; orientation tuning: $0.855 \pm$ $0.016, n=82$; overall: $0.915 \pm 0.006, n=297)$. Only the fittings with $R^{2}$ values larger than 0.5 were included in further analysis.

Testing LGN input to SINs. For some LGN cells and cortical SINs, cross-correlograms were generated from simultaneously recorded spontaneous spike trains. Functional connectivity between these pairs was accessed by searching for a peak in the correlogram at intervals of 1.1-2.5 $\mathrm{ms}$ following the LGN spike. This peak was defined by the presence, within this $1.5 \mathrm{~ms}$ window, of two bins of three successive bins, each showing significantly higher firing rate than baseline activity (measured by activity between $-4 \mathrm{~ms}$ and $+1 \mathrm{~ms}$ of the LGN spike time). When a significant peak was detected, onset latency and peak latency were measured as the relative timing of the first and highest bin in the peak, respectively, and an "efficacy" value was calculated based on a brief window (peak $\pm 0.6 \mathrm{~ms}$ ) by counting the number of SIN spikes that occurred during this window, subtracting the baseline, and dividing this value by the number of total LGN spikes (Swadlow and Gusev, 2002).

All the $p$ values provided in Results represent the results of independent sample $t$ test, if not specified. Data are provided as \pm SEM.

\section{Results}

We recorded 109 cells in layer 4 of primary visual cortex from 3 female rabbits. Sixty-two of these were simple cells (56.9\%), 33 were SINs (30.3\%), and 14 could not be placed into either category, and were defined as "other" cells (12.8\%, Table 1). These 
Table 1. Cell numbers of each group

\begin{tabular}{lcc}
\hline Cell type & Number of cells & \% of whole population \\
\hline Simple cells & 62 & $56.88 \%$ \\
$\quad$ Sustained & 27 & $24.77 \%$ \\
Transient & 19 & $17.43 \%$ \\
$\quad$ Sus/Tran unclassified & 16 & $14.68 \%$ \\
SINs & 33 & $30.28 \%$ \\
$\quad$ Sustained & 8 & $7.34 \%$ \\
$\quad$ Transient & 25 & $22.94 \%$ \\
Other & 14 & $12.84 \%$ \\
All & 109 & $100 \%$ \\
\hline
\end{tabular}

Sus, Sustained; Tran, transient.

other cells were not studied in detail. Receptive field properties are summarized in Table 2.

\section{Cell classification, spike duration, and responses to thalamic stimulation}

Many extracellular studies rely on spike duration for cell classification. Here, SINs were identified by a discharge of three or more spikes to thalamic stimulation at frequencies exceeding $600 \mathrm{~Hz}$ (Fig. 1A). SINs had significantly shorter spike durations $(0.590 \pm$ $0.017 \mathrm{~ms})$ than simple cells $(1.539 \pm 0.126 \mathrm{~ms}, p<0.001)$, and only one SIN (3\%) had a spike duration longer than $0.8 \mathrm{~ms}$. By contrast, 52 simple cells $(84 \%)$ had spike durations longer than $0.8 \mathrm{~ms}$. A small number of simple cells did, however, have very short spike durations. Spike waveforms of three simple cells and one SIN are shown in Figure $2 A 1-D 1$, inset). The distribution of spike durations of these populations showed some overlap (Fig. $1 B)$. Moreover, the overall distribution was not significantly bimodal (Hartigan's test, $p=0.116$ ).

SINs also had significant shorter latencies (Fig. 1C) to synaptic activation via thalamic stimulation $(1.794 \pm 0.087 \mathrm{~ms})$ than simple cells $(3.174 \pm 0.124 \mathrm{~ms}, p<0.001)$. Whereas all but three SINs (90.9\%) had latencies of $<2 \mathrm{~ms}, 47 / 54$ simple cells $(87 \%)$ that responded to thalamic stimulation had latencies $>2 \mathrm{~ms}$. Simple cells not only had longer latencies, but also responded to thalamic stimulation with fewer spikes (usually 1 spike) than SINs (by definition, at least three spikes, median value $=4$ spikes). Simple cells also showed higher thresholds to thalamic stimulation than SINs (53 simple cells vs 33 SINs, $6.1 \pm 0.09 \mathrm{~V}$ vs $1.8 \pm 0.02 \mathrm{~V}, p<0.001)$.

By virtue of our criteria for identification, SINs were required to respond to thalamic stimulation with three or more spikes, at minimal interspike intervals (ISIs) of $<1.67 \mathrm{~ms}(600 \mathrm{~Hz})$. Figure $1 D$ shows these minimal ISIs for SINs and for cells that did not meet this criterion. The great majority of simple cells responded with only one spike ( 47 cells) or no spikes ( 8 cells) to thalamic stimulation (Fig. $1 D$, right column), and only two simple cells had minimal ISIs of $<1.6 \mathrm{~ms}$. These latter two cells were not classified as SINs because they responded with only two (not three) spikes to thalamic stimulation.

\section{Spatial structure of the RF}

RF maps of each sign (ON or OFF) were obtained from all simple cells and SINs by reverse correlation method. Simple cells were of the "S1" variety, with a single ON $(n=28)$, or OFF $(n=25)$ subfield or the "S2" variety, with parallel ON and OFF subregions $(n=9)$. Please note, by applying a threshold as $30 \%$ of peak response to remove noise (methods), we may underestimate the population of S2 simple cells due to the possibility of cutting off very weak subfields. For the identified S2 simple cells, the alignment of $\mathrm{ON}$ and OFF subfields was in agreement with their pre- ferred orientation (i.e., the preferred orientation was predictable from the position of the subfield maxima, mean deviation was 10.6 degrees, maximum deviation was 30 degrees). By contrast, all SINs possessed overlapped ON and OFF subfields. Figure 2 shows examples of the RF maps of one ON S1 simple cell (A1), one OFF S1 simple cell (B1), one S2 simple cell (C1), and one SIN (D1).

In visual cortex, simple/complex classification is often based on the spatial separation of the cell's ON/OFF subfields, with simple cells having separated ON/OFF subfields and complex cells having overlapped ON/OFF subfields (Hubel and Wiesel, 1962; Hirsch and Martinez, 2006). Here, we used the LSI to measure the overlap of the cell's ON/OFF subfields. LSI takes value from $0-1$, with lower value meaning less overlap and more ONOFF separation and higher value meaning more overlap and less ON-OFF separation (see Materials and Methods). The LSI distribution of all cells was significantly bimodal (Hartigan's test, $p<0.001$, Fig. $3 A, B)$, with all simple cells having LSI $<0.2$ $(0.028 \pm 0.007)$ and all SINs having LSI $>0.3(0.666 \pm 0.023)$. This means that all simple cells had single unipolar subfield or separate ON/OFF subfields and all SINs had overlapping ON/ OFF subfields. It is not surprising that simple cells had low LSI, as this was our classification criterion. What is notable is the finding that all SINs had overlapping ON/OFF subfields (i.e., complex), considering that our SINs were defined solely on their responses to thalamic electrical stimulation. Simple cells also showed significantly smaller dominant subfield width $(3.169 \pm 0.131 \mathrm{deg})$ and dominant subfield area $\left(9.713 \pm 0.692 \mathrm{deg}^{2}\right)$ than SINs (width: $8.739 \pm 0.568 \mathrm{deg}, p<0.001$; area: $61.738 \pm 7.677 \mathrm{deg}^{2}$, $p<0.001$; Fig. $3 C, D)$. Although the distributions of dominant subfield width and area were not significantly bimodal (Hartigan's test, for dominant subfield width $p=0.816$, for dominant subfield area $p=0.776$ ), these measures do enhance the segregation between simple cells and SINs by RF properties (Fig. $3 A$ ).

\section{Spontaneous activity}

The spontaneous firing rates of simple cells and SINs were dramatically different, with all simple cells having a spontaneous rate $<2$ spk/s (mean: $0.551 \pm 0.084 \mathrm{spk} / \mathrm{s}, n=28$ ), and all SINs having a spontaneous rate $>5 \mathrm{spk} / \mathrm{s}$ (mean: $21.955 \pm 2.182 \mathrm{spk} / \mathrm{s}, n=19, p<$ $0.001)$. Our data further reveal that the spontaneous firing rate distribution of these cells was significantly bimodal on logarithmic scale (Hartigan's test, $p<0.001$, Fig. $4 A$ ), with two peaks (each formed by single type of cells) having no overlap at all.

\section{F0 and F1 responses, spatial summation linearity, and reliability}

After mapping the RF, we measured the cell's response to its optimal drifting grating and calculated the maximum F0 response (with or without spontaneous firing rate subtracted), maximum F1 response, F1/F0 ratio, and Fano factor. Examples of perievent rasters (Fig. 2A2-C2 for simple cells, D2 for SIN) and PSTHs (Fig. 2A3-C3 for simple cells, D3 for SIN) to optimal drifting gratings of simple cells and a SIN are shown in Figure 2. Among these examples, simple cells were strongly modulated at the frequency of the drifting grating while SINs responded with pronounced increase in mean rate superimposed to a weak sinusoidal modulation.

Both maximum F0 responses (Fig. $4 B$ ) and maximum F1 responses (Fig. 4C) were higher in SINs than in simple cells and these differences were highly significant (F0: 57 simple cells vs 30 SINs, $9.612 \pm 0.926 \mathrm{spk} / \mathrm{s}$ vs $59.764 \pm 4.204 \mathrm{spk} / \mathrm{s}, p<0.001 ; \mathrm{F} 1$ : $14.422 \pm 1.506 \mathrm{spk} / \mathrm{s}$ vs $32.965 \pm 3.727 \mathrm{spk} / \mathrm{s}, p<0.001)$. Bimo- 
Table 2. Comparisons between Layer 4 simple cells and SINs

\begin{tabular}{|c|c|c|c|c|c|}
\hline & Layer 4 simple cells & Layer 4 SINs & Significance & Overlap distribution? & Bimodality (Hartigan) test \\
\hline Spike duration (ms) & $1.54 \pm 0.12$ & $0.59 \pm 0.02$ & $* * * b$ & YES & N.S. \\
\hline Spont activity (spk/s) & $0.55 \pm 0.08$ & $21.96 \pm 2.18$ & $* * * b$ & NO & $* * *$ \\
\hline Latency to flash stimulation (ms) ${ }^{a}$ & 34.22 & 28.16 & $* * * c$ & YES & N.S. \\
\hline Evoked F0 (spk/s) & $9.61 \pm 0.93$ & $59.76 \pm 4.20$ & $* * * b$ & NO & $* *$ \\
\hline Evoked F0 w/o spont (spk/s) & $7.51 \pm 1.01$ & $31.94 \pm 3.76$ & $* * * b$ & YES & N.S. \\
\hline Evoked F1 (spk/s) & $14.42 \pm 1.51$ & $32.97 \pm 3.73$ & $* * * b$ & YES & N.S. \\
\hline RF subfield structure (local similarity index) & Segregated/unipolar (0.028 \pm 0.007$)$ & Overlapped $(0.666 \pm 0.023)$ & $* * * b$ & NO & $* * *$ \\
\hline RF subfield width (deg) & $3.17 \pm 0.13$ & $8.74 \pm 0.57$ & $* * * b$ & YES & N.S. \\
\hline Spatial summation (F1/F0 ratio) & Linear $(1.50 \pm 0.04)$ & Nonlinear $(0.53 \pm 0.04)$ & $* * * b$ & YES & N.S. \\
\hline Fano factor & $1.15 \pm 0.10$ & $1.33 \pm 0.08$ & N.S. ${ }^{b}$ & YES & N.S. \\
\hline Orientation selectivity index & $0.81 \pm 0.02$ & $0.17 \pm 0.02$ & $* * * b$ & YES & $* *$ \\
\hline Circular variance & $0.53 \pm 0.03$ & $0.94 \pm 0.01$ & $* * * b$ & YES & N.S. \\
\hline Direction selectivity index & $0.69 \pm 0.03$ & $0.11 \pm 0.02$ & $* * * b$ & YES & $* * *$ \\
\hline $\mathrm{C} 50(\%)^{d}$ & $27.17 \pm 2.65$ & $10.83 \pm 1.94$ & $* * * b$ & YES & N.S. \\
\hline Peak SF (cpd) & $0.20 \pm 0.02$ & $0.22 \pm 0.05$ & N.S. ${ }^{b}$ & YES & N.S. \\
\hline SF bandwidth (oct) & $0.71 \pm 0.07$ & $1.20 \pm 0.10$ & $* * * b$ & YES & N.S. \\
\hline Peak TF $(\mathrm{Hz})$ & $5.58 \pm 0.57$ & $6.26 \pm 0.98$ & N.S. ${ }^{b}$ & YES & N.S. \\
\hline TF bandwidth (oct) & $2.87 \pm 0.17$ & $4.70 \pm 0.43$ & $* * * b$ & YES & N.S. \\
\hline
\end{tabular}

Spont, Spontaneous; RF, receptive field; SF, spatial frequency; TF, temporal frequency.

${ }^{* *} p<0.01 ;{ }^{* * *} p<0.001 ;$ N.S.: $p>0.05$.

${ }^{a}$ Median.

${ }^{b}$ Independent $t$ test.

'K-S test.

${ }^{d}$ C50s are different between sustained and transient cells. Refer to Table 3 for results of simple cells and SINs breaking down into sustained and transient groups.

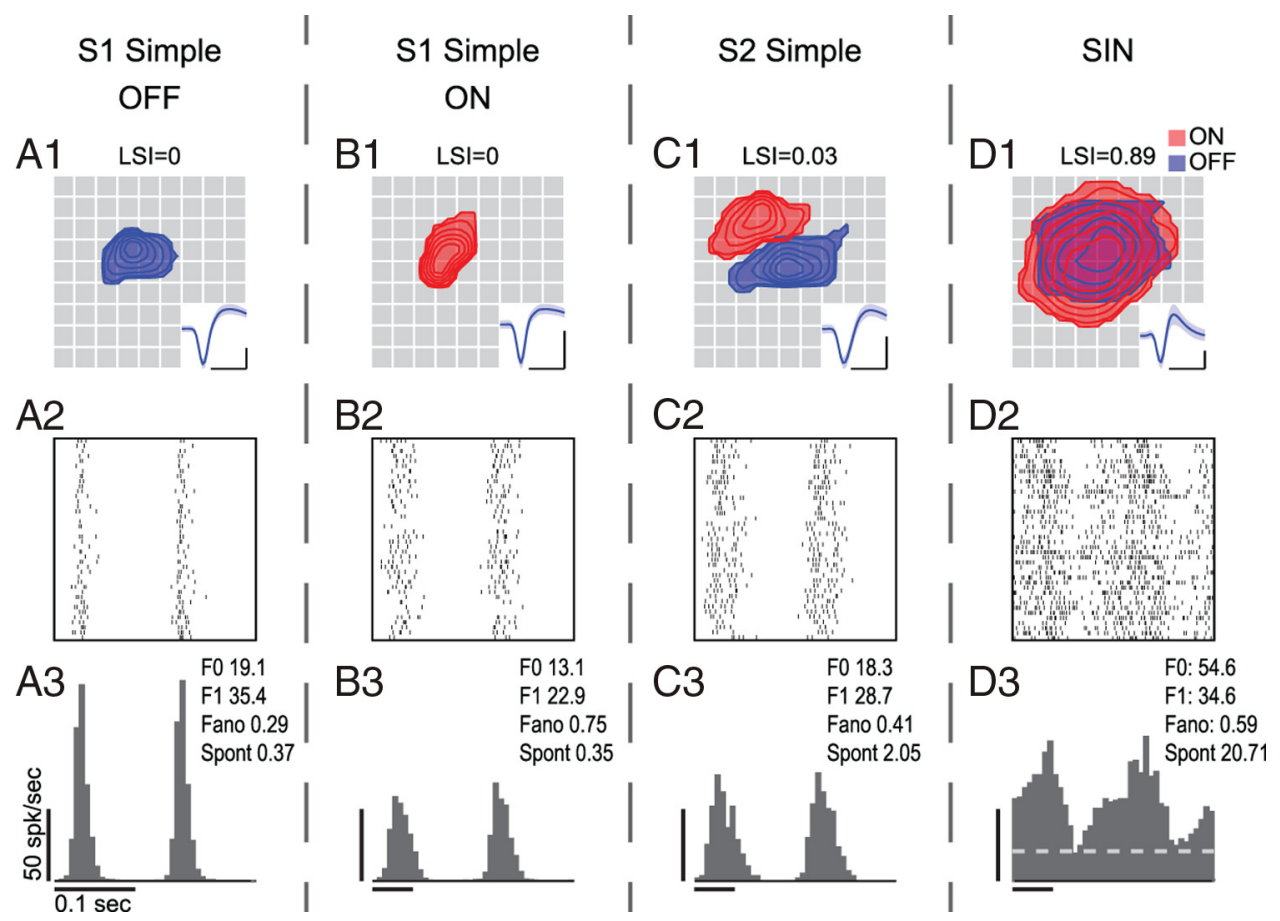

Figure 2. Receptive field maps, spike waveforms, perievent rasters, and PSTHs of three simple cells and a SIN. $\boldsymbol{A 1}-\boldsymbol{A 3}$, An example of S1 0FF simple cells. $\boldsymbol{A} \mathbf{1}$, Receptive field maps, grid scale: 1 degree, each contour: $12 \%$ of peak value. LSIs were shown on top of the maps. Inset, Spike waveforms, calibration: $0.4 \mathrm{ms,} 0.1 \mathrm{mV}$. Shadowed areas represent mean \pm SD. A2, Perievent rasters for two periods. For reasons of clarity, only first 40 iterations were shown. A3, PSTHs. F0 responses, F1 responses, Fano factors, and spontaneous activity were listed on the upper right corner. Unit for F0, F1, and spontaneous activity: spk/s. B1-B3, An example of S1 ON simple cell. C1-C3, An example of S2 simple cell. D1-D3, An example of SIN. Gray dashed line in D3 shows the spontaneous activity level for the SIN. The spontaneous activity levels for simple cells are too low to indicate with a dashed line.

dality was seen in maximum F0 distribution (Hartigan's test: $p=$ 0.007, Fig. $4 B$ ) but not in maximum F1 distribution (Hartigan's test: $p=0.701$, Fig. $4 C$ ).

The F1/F0 ratio is a common method to test the linearity of spatial summation in the RF and has been frequently used as a criterion to define simple and complex cells (Skottun et al., 1991). Due to the differences in linearity of spatial summation, the F1/F0 ratio should be $>1$ for simple cells and $<1$ for complex cells. In this study, we measured the linearity of spatial summation (F1/F0 ratio) in 57 simple cells and 30 SINs. All but a few simple cells (94.74\%) had F1/F0 ratios $>1$ (mean for all simple cells: $1.497 \pm$ 0.036 ), and all SINs had F1/F0 ratios $<1$ (mean for all SINs: $0.532 \pm 0.039$, simple vs SIN: $p<0.001$, Fig. $4 D$ ). Thus, SINs showed features of complex cells in terms of spatial summation 
linearity, as they did in terms of spatial RF structure. However, although two peaks are evident in the overall histogram shown in Figure 4D, Hartigan's test for bimodality did not reach statistical significance $(p=0.247)$. Moreover, the distribution of F1/F0 lost any appearance of bimodality when we subtracted the spontaneous activity (Hartigan's test, $p=$ 0.975 , see below; Fig. $4 D$, inset, below).

The reliability of visual responses is an important factor in information transmission and is usually quantified as a variance/mean ratio called Fano factor (Kara et al., 2000; Alitto et al., 2011). Cells with highly reliable visual responses and limited variability from trial to trial (low variance) should have a low Fano factor while cells that are more variable should have higher Fano factors. We measured the Fano factors of 30 simple cells and 18 SINs under drifting grating stimulation, using a full grating cycle as the time bin. In these cells, we collected a large number of spikes (simple: $6140 \pm 788$ spikes; SINs: $66,322 \pm 6499$ spikes) to make the measurements of Fano factor as accurate as possible. We found no significant difference between simple cells and SINs in the average Fano Factor (simple cells vs SINs, $1.153 \pm 0.096$ vs $1.330 \pm 0.077, p=$ $0.206)$ and the two groups combined showed no hint of bimodality (Hartigan's test, $p=0.790$; Fig. 4E).

\section{Orientation and direction selectivity}

Measurements of orientation/direction tuning curves in 55 simple cells and 27 SINs demonstrate that simple cells are much better tuned to orientation/direction than SINs. Figure 5 shows orientation tuning curves from three simple cells (left) and three SINs (right). The simple cells were sharply tuned and two of the three were responding to only one direction (Fig. $5 A, B$ ) while the other one responded to both directions (Fig. $5 C$ ). All three SINs were unselective to orientation/direction (Fig. 5D-F). The distribution of OSI was significantly bimodal (Fig. 6A, Hartigan's test, $p=0.002$ ) with simple cells forming a peak around high OSI $(0.803 \pm 0.024)$ and SINs forming another peak around low OSI $(0.175 \pm 0.015)$. The distribution of DSI was also significantly bimodal (Hartigan's test, $p<0.001$, Fig. $6 B$ ). However, although simple cells had significantly higher DSI than SINs $(0.683 \pm 0.034$ vs $0.107 \pm 0.016, p<0.001)$, some simple cells were orientation selective but not direction selective (Fig. 6C). In summary, all simple cells were orientation selective and most were direction selective, while no SINs showed either direction selectivity or orientation selectivity. Since OSI and DSI are calculated from only 2-3 data points from tuning curves, they may not describe completely the orientation/ direction tuning of layer 4 cells. To document more completely these properties we also measured circular variance (Levick and Thibos, 1982; Ringach et al., 1997; Ringach et al., 2002), which uses all data points in the entire orientation/direction cycle. Circular variance takes values from 0 to 1 , with lower values meaning tighter orientation tuning and higher values meaning broader orientation tuning. Consistent with OSIs, simple cells had significantly lower circular
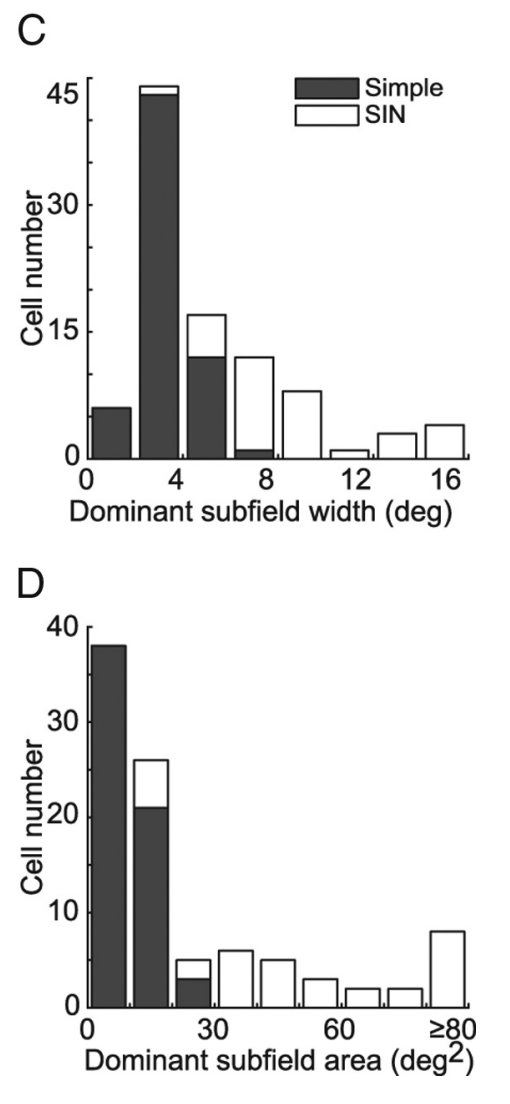

80

00
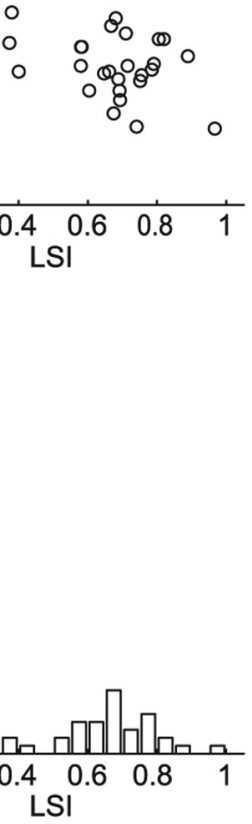

Figure 3. Receptive field subfield structures of simple cells and SINs. A, Scatter plot of $L S I$ against dominant subfield width from all simple cells and SINs. B, Distribution of LSI. C, Distribution of dominant subfield width. D, Distribution of dominant subfield area.

variance than SINs (simple vs SIN, CirVar, $0.526 \pm 0.030$ vs $0.937 \pm$ $0.010, p<0.001$, Fig. $6 D$ ). Notably, no SIN had a circular variance lower than 0.8 , emphasizing a pronounced lack of orientation selectivity. As expected, the circular variance was highly correlated with the orientation selectivity in both SINs and simple cells (Fig. 6D, inset).

The preferred direction and orientation distribution of simple cells (Fig. 6E,F) show that most our simple cells prefer approximately horizontal orientations and up/down directions with a bias <30 degrees, which is consistent with previous studies (Bousfield, 1977; Murphy and Berman, 1979; Swadlow and Weyand, 1987). S2 simple cells showed significantly larger OSIs than S1 simple cells (S2 vs S1: $0.9 \pm 0.026 n=8$ vs $0.797 \pm 0.026 n=$ $46, p=0.009$ ), suggesting that $S 2$ simple cells respond less to the orthogonal orientation than S1 simple cells. The circular variances of S2 cells also suggested more selectivity than those of S1 cells, but this difference did not reach statistical significance (S2 vs S1: $0.410 \pm 0.067$ vs $0.547 \pm 0.033$, respectively, $p=0.108$ ). There were no significant differences in the DSIs between S2 and S1 simple cells (S2 vs S1, DSI, $0.685 \pm 0.085$ vs $0.694 \pm$ $0.036, p=0.923)$.

As noted, the above results concerning orientation/direction tuning were derived from F1 responses of simple cells and F0 responses from SINs (see Materials and Methods). This is because $\mathrm{F} 1$ and $\mathrm{F} 0$ responses represent the dominant responses for linear simple cells and nonlinear SINs, respectively (see results of $\mathrm{F} 1 / \mathrm{F} 0$ ratio), and it is a common way to analyze simple and complex cells in visual cortex (Hawken et al., 1996; O'Keefe et al., 1998; Contreras and Palmer, 2003; Cardin et al., 2007). Interestingly, although the F0 responses of all SINs are unselective to orientation and direction as described above, the F1 responses of 
A

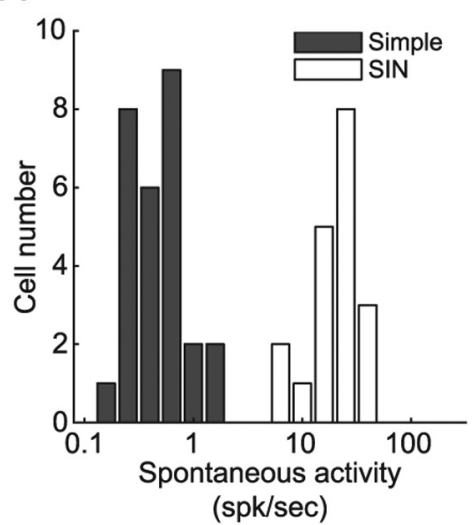

B

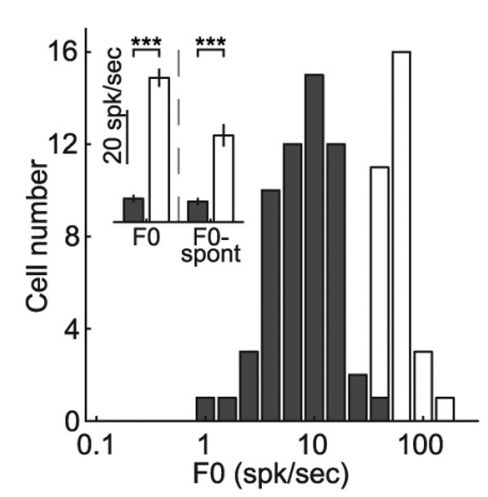

C

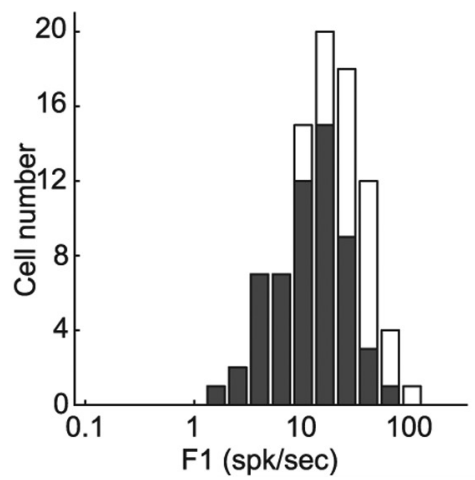

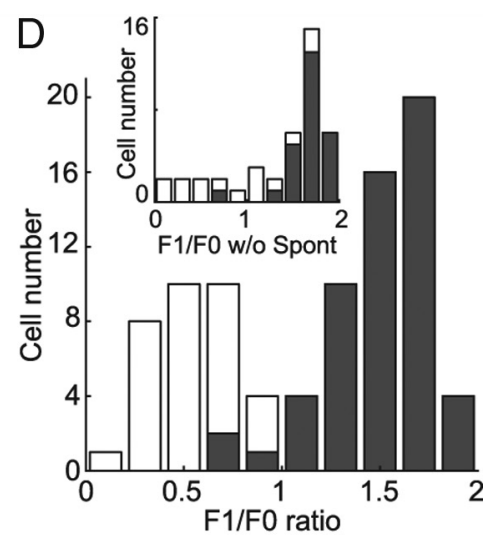

E

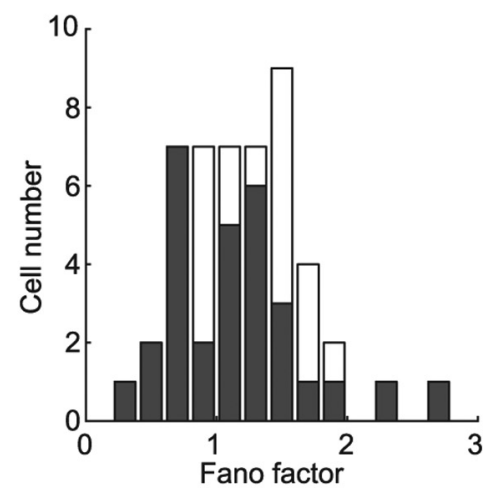

diagonal line (correlation coefficient, CirVar: 0.970 Fig. $7 B$, OSI:0.926 Fig. 7C, DSI: 0.944 Fig. $7 D$ ), which is consistent with previous measurements in macaque $\mathrm{V} 1$ (Ringach et al., 2002). By contrast, the results from SINs deviated strongly from the diagonal line because their $\mathrm{F} 1$ responses can be more orientation or direction selective than F0 responses (Fig. $7 B-D$ ). Population statistics also indicated that the $\mathrm{F} 1$ responses of SINs were more orientation/direction selective than the F0 responses (paired $t$ test, F1 vs F0, OSI: $0.428 \pm 0.040$ vs $0.181 \pm$ $0.017, p<0.001$; DSI: $0.287 \pm 0.047$ vs $0.112 \pm 0.018, p=0.002$; CirVar: $0.833 \pm$ 0.026 vs $0.935 \pm 0.011, p<0.001$, Fig. $7 E)$. Note, however, that although the F1 responses of some SINs showed orientation/ direction selectivity to some extent, the selectivity was not as pronounced as in simple cells (simple F1 vs SIN F1, OSI: $0.817 \pm$ 0.023 vs $0.428 \pm 0.040, p<0.001$; DSI: $0.695 \pm 0.034$ vs $0.287 \pm 0.047, p<0.001$; CirVar: $0.513 \pm 0.031$ vs $0.833 \pm 0.026, p<$ 0.001 , Fig. $7 E$ ). Moreover, the $\mathrm{F} 1$ responses of SINs were clearly smaller than the F0 responses even at their preferred orientations (Fig. 7A).

\section{Sustained/transient classification and contrast tuning}

Simple cells and SINs can generate either sustained or transient responses when presented with optimal stationary stimulus. We studied this response property by quantifying a SI, which was defined as the ratio between the cell's maintained firing rate (measured 0.5-1.0 s after stimulus presentation) and the baseline firing rate (measured during the one second or half second before stimulus onset). Cells with SIs $<2$ were classified as transient cells. Cells with SIs $>2$ and an absolute maintained firing rate $>1 \mathrm{spk} / \mathrm{s}$ were classified as sustained cells. The remaining cells (with SIs $>2$ but absolute maintained firing rate $<1 \mathrm{spk} / \mathrm{s}$ ) remained unclassified with respect to the sustained/ transient distinction. Based on these criteria, we classified 27 simple cells as sustained (SI: $14.100 \pm 3.689$ ), 19 as transient (SI: $0.651 \pm$ firing rates. $\boldsymbol{B}$, Distribution of F0 responses to optimal drifting gratings. Inset, SINs had significantly higher F0 responses than simple cells with or without spontaneous activity removed. ${ }^{* * *} p<0.001$. C, Distribution ofFO responses to optimal drifting gratings. D, Distribution of F1/F0 ratios. Inset, Distribution of F1/F0 ratios after removing spontaneous activity. $\boldsymbol{E}$, Distribution of Fano factors.

some SINs show considerable orientation and/or direction selectivity (Fig. 7), despite the fact that they are weaker than F0 responses in all directions. Figure $7 A$ shows orientation tuning curves from both F0 and F1 responses of three SINs. The F0 responses of these three SINs did not present strong orientation/direction selectivity. However, their F1 responses were strikingly diverse and showed no orientation selectivity (Fig. 7A, left), strong orientation selectivity (Fig. 7A, middle), or strong direction selectivity (Fig. $7 A$, right). So, we compared the orientation tuning properties between F0 and F1 response for both simple cells and SINs (Fig. 7B-E). For simple cells, all three measurements (OSI, DSI, and circular variance) calculated from F1 responses strongly correlated with those from $\mathrm{F} 0$ responses, and all data points distributed tightly around the
0.126 ), and 16 as sustained/transient unclassified. Of the 33 SINs studied, 8 were sustained (SI: $2.541 \pm 0.363$ ) and 25 were transient (SI: $1.040 \pm 0.082$ ). Figure 8 shows PSTHs to optimal stationary stimuli from one sustained simple cell (Fig. $8 A$ ), one transient simple cell (Fig. $8 B$ ), one sustained SIN (Fig. $8 C$ ), one transient SIN (Fig. $8 D$ ), as well as the population averages of these four groups (Fig. $8 E, F)$. Figure $8, G$ and $H$, show the distribution of SIs for simple cells and SINs, respectively, on logarithmic scale. Note that simple cells are significantly more likely to be sustained than SINs $\left(X^{2}\right.$ test, $p=$ 0.006).

Sustained and transient cells had similar average latencies to electrical stimulation (sustained vs transient, simple cells: 


\section{Simple cell}

A
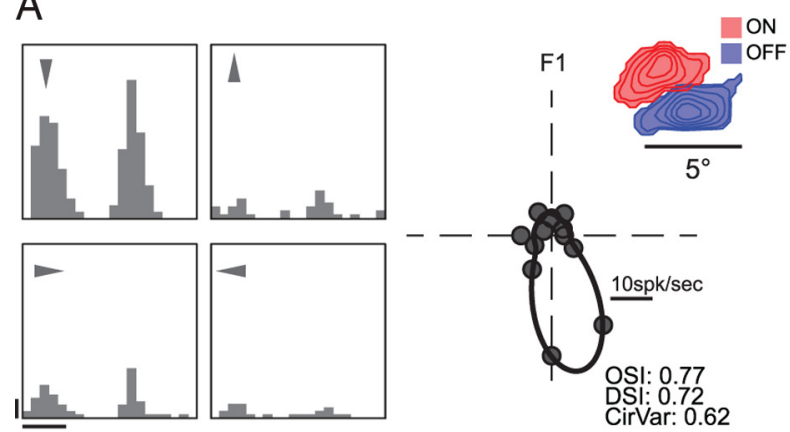

B
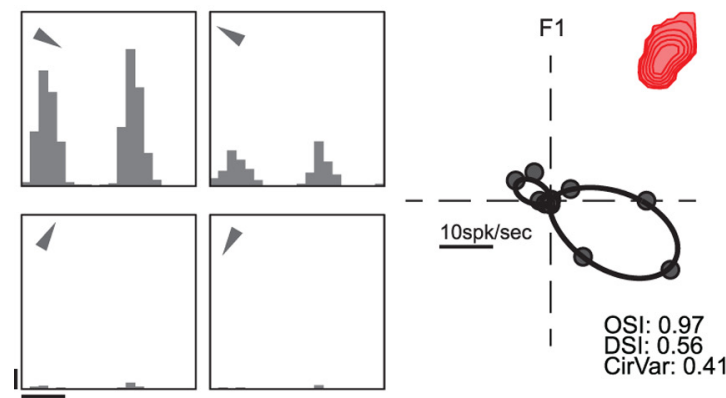

C
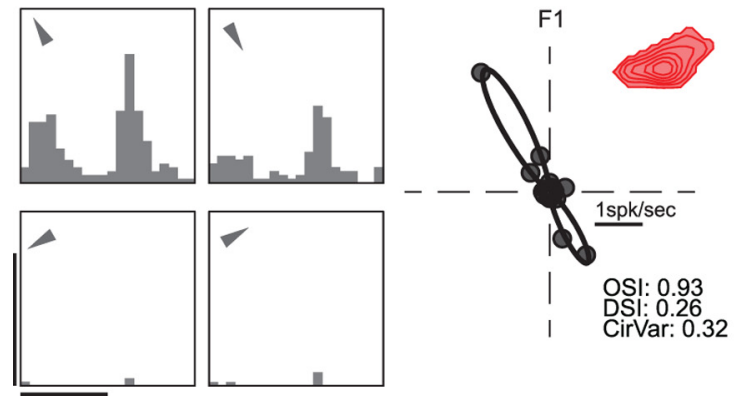

SIN

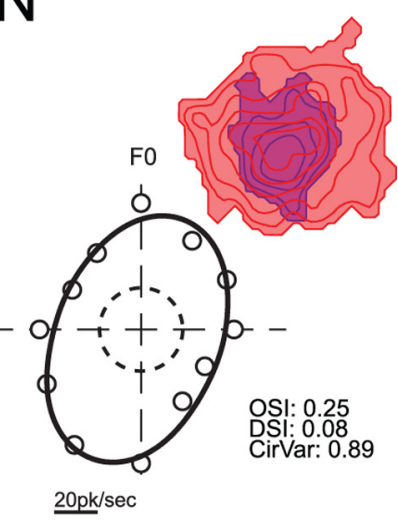

E

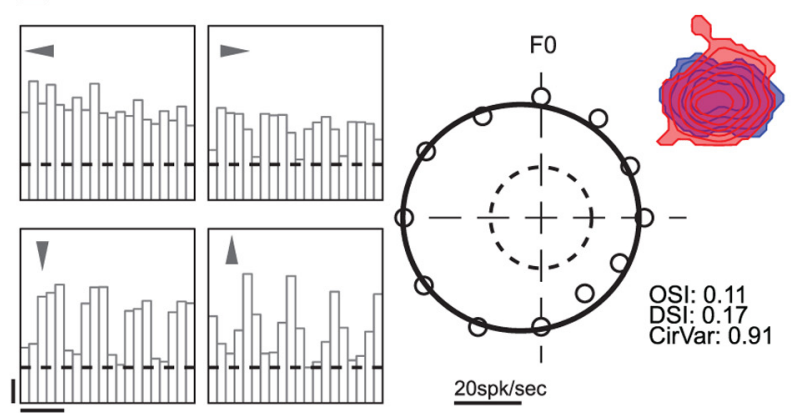

F
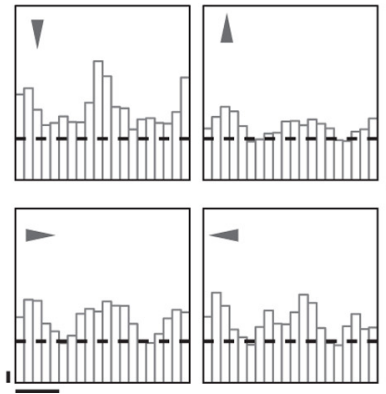

$\underline{20 \mathrm{spk} / \mathrm{sec}}$

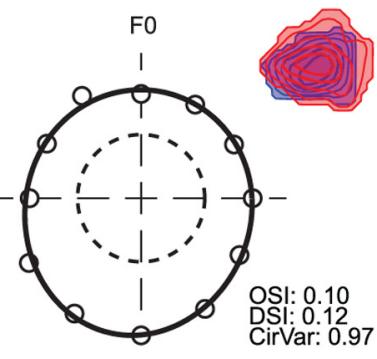

Figure 5. Receptive field structures and orientation tunings of three simple cells $(\boldsymbol{A}-\boldsymbol{C})$ and three $\operatorname{SINs}(\boldsymbol{D}-\boldsymbol{F})$. For each cell, left part shows the PSTHs to drifting gratings in four example directions (designated by the arrowheads located at upper left corner of the box). Each PSTH plots 2 periods of the stimulation. Calibration: $10 \mathrm{spk} / \mathrm{s}, 0.25 \mathrm{~s}$. Right part shows the orientation tuning curves (fitted by von Mises distribution function, F1 for simple cells and FO for SINs). Top right part shows the receptive subfields of the cell, each contour: $12 \%$ of peak value. Note that $A$ represents the same cell shown in Figure 2 and $B$ represents the same cell shown in Figure 2B. The dashed lines in PSTHs and tuning curves of SINs indicate their spontaneous activity levels. The spontaneous activity levels for simple cells are too low to indicate with a dashed line.

$3.139 \pm 0.198 \mathrm{~ms}$ vs $3.189 \pm 0.193 \mathrm{~ms}, p=0.861 ;$ SINs: $1.638 \pm$ $0.075 \mathrm{~ms}$ vs $1.844 \pm 0.112 \mathrm{~ms}, p=0.318$ ), spike durations (simple cells: $1.632 \pm 0.213 \mathrm{~ms}$ vs $1.302 \pm 0.141 \mathrm{~ms}, p=0.253$; SINs: $0.603 \pm 0.036 \mathrm{~ms}$ vs $0.586 \pm 0.019 \mathrm{~ms}, p=0.660$ ), LSI (simple cells: $0.017 \pm 0.008$ vs $0.044 \pm 0.015, p=0.130$; SINs: $0.691 \pm$ 0.061 vs $0.658 \pm 0.024, p=0.545$ ), spontaneous activity (simple cells: $0.444 \pm 0.055 \mathrm{spk} / \mathrm{s}$ vs $0.851 \pm 0.288 \mathrm{spk} / \mathrm{s}, p=0.211$; SINs: $17.799 \pm 4.876 \mathrm{spk} / \mathrm{s}$ vs $23.064 \pm 2.445 \mathrm{spk} / \mathrm{s}, p=0.339), \mathrm{F} 1 / \mathrm{F} 0$ ratio (simple cells: $1.542 \pm 0.041$ vs $1.441 \pm 0.077, p=0.213$; SINs: $0.499 \pm 0.107$ vs $0.543 \pm 0.041, p=0.641)$, Fano factor (simple cells: $1.155 \pm 0.129$ vs $1.254 \pm 0.219, p=0.679$; SINs: $1.161 \pm 0.139$ vs $1.414 \pm 0.086, p=0.125$ ), OSI (simple cells: $0.805 \pm 0.037$ vs $0.845 \pm 0.042, p=0.481$; SINs: $0.197 \pm 0.029$ vs $0.165 \pm 0.018, p=0.356$ ), DSI (simple cells: $0.709 \pm 0.046$ vs $0.742 \pm 0.071, p=0.684$; SINs: $0.117 \pm 0.034$ vs $0.104 \pm 0.019$, $p=0.720$ ), and circular variance (simple cells: $0.524 \pm 0.053$ vs $0.486 \pm 0.051, p=0.624$; SINs: $0.929 \pm 0.022$ vs $0.941 \pm 0.011$, $p=0.611$ ). However, they showed striking differences in their contrast response functions (especially for simple cells), as illustrated in Figure $9 A-D$ for the four example cells from Figure $8 A-D$, respectively, and in Figure 9, $E$ and $F$, for the normalized population average (sustained and transient simple cells, Fig. 9E; sustained and transient SINs, Fig. $9 F$ ). The sustained simple cells were less sensitive to low contrasts (had significantly higher C50s) than the transient simple cells (C50, sustained simple cells: $33.038 \pm 3.942 \%, n=21$; transient simple cells: $11.930 \pm$ 2.170\%, $n=10, p<0.001$, Fig. 9G). Sustained SINs also had higher C50s $(16.971 \pm 5.219 \%, n=7)$ than transient SINs $(8.444 \pm 1.556 \%, n=18)$, however, this difference was not significant $(p=0.161$, Fig. $9 G)$. The inset in Figure $9 E$ shows the 
A

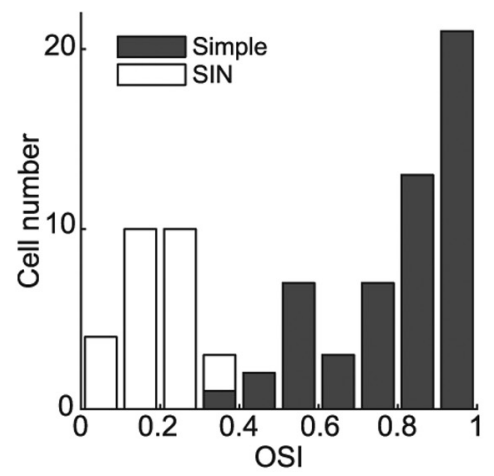

B

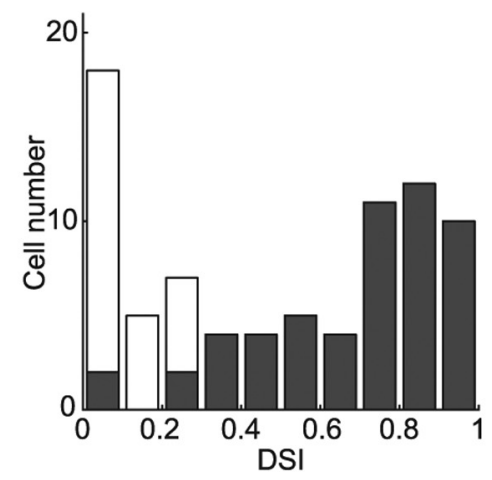

C

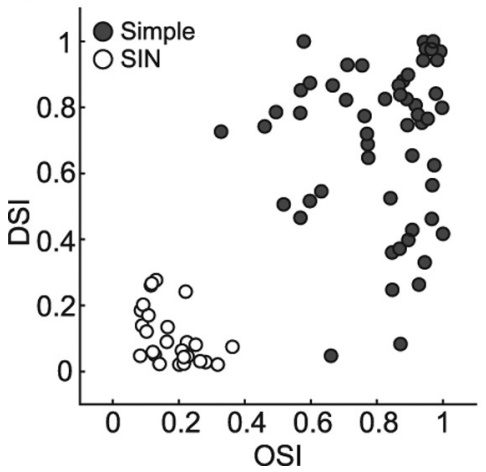

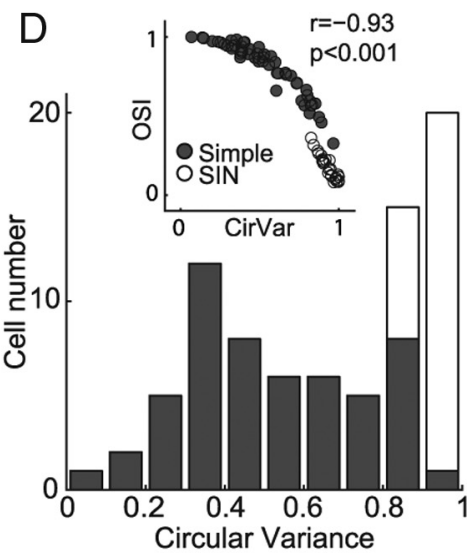

$E$ Simple cells

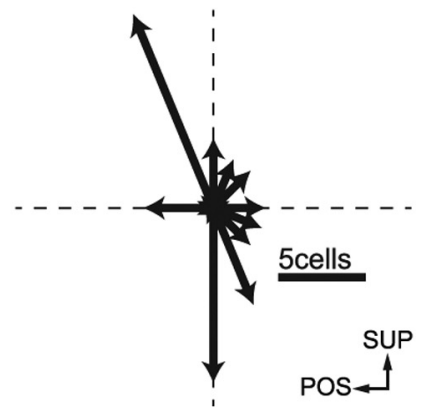

Preferred direction distribution

$\mathrm{F}$

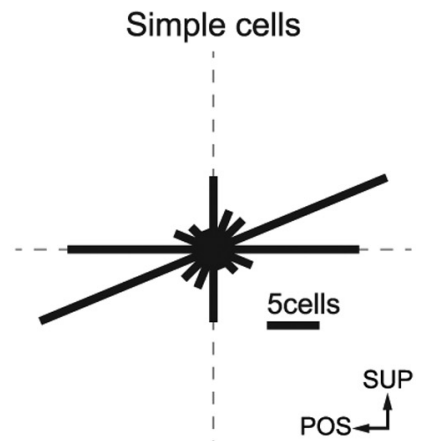

Preferred orientation distribution

Figure 6. Orientation and direction tuning properties of simple cells and SINs. A, Distribution of OSIs. B, Distribution of DSIs. $\boldsymbol{C}$, Scatter plot of OSIs against DSIs. $\boldsymbol{D}$, Distribution of CirVars. Inset, OSI and CirVar are significantly correlated. $\boldsymbol{E}$, Distribution of preferred directions of simple cells. Length of the each arrow represents frequency. $\boldsymbol{F}$, Distribution of preferred orientations of simple cells. Orientation of each bar represents the orientation of stimulating drifting grating. Length of the each bar represents frequency. SUP, Superior; POS, posterior.

population average response for sustained and transient LGN neurons in alert rabbits (from Cano et al., 2006). Note that the differences in the contrast response functions of layer 4 sustained and transient simple cells are very similar to those of the sustained and transient LGN neurons, respectively. However, unlike LGN transient cells, transient simple cells showed a certain level of high-contrast suppression: they responded to intermediate contrasts better than to high contrasts (Fig. 9E). This phenomenon was very prominent in some simple cells. For the example cell illustrated in Figure $9 B$, the response at intermediate contrasts was almost twice as strong as at the highest contrast. We calculated the percentage of the cells that showed high-contrast suppression in each of the four groups (sustained simple cells, transient simple cells, sustained SINs, and transient SINs). Transient cells were more likely to show high-contrast suppression than sustained cells, especially if they were simple cells. High-contrast suppression could be demonstrated in 50\% (5 of 10) of transient simple cells, $33.33 \%$ (6 of 18 ) of transient SINs, $28.57 \%$ (6 of 21 ) of sustained simple cells, and $28.57 \%$ ( 2 of 7 ) of sustained SINs (Fig. 9H). Whether the cell showed high-contrast suppression or not was decided by the best fit of the cell's contrast tuning curve (fit with or without high-contrast suppression). We used $R_{\text {nor }}{ }^{2}$ as the criterion for goodness of fitting to control for the additional parameter used in the fit with high-contrast suppression (see Materials and Methods). By using this justification, we controlled the effect of noisy fluctuation of contrast response functions and limited the possibility of false positive identification of high-contrast suppression. In summary, our results demonstrate that transient cells are very sensitive to low contrasts and are more likely to show high-contrast suppression. By contrary, sustained cells are less sensitive to low contrasts and more likely to increase their responses monotonically with contrast. The differences in the contrast response function between sustained and transient cells are more prominent in simple cells than in SINs.

\section{Latency to flash stimulation}

Simple cells showed significantly longer latencies to flash visual stimuli than SINs [median for 57 simple cells: $34.22 \mathrm{~ms}$; median for 33 SINs: $28.16 \mathrm{~ms}, p<0.001$, Kolmogorov-Smirnov test (K-S test)], and sustained cells ( simple cells and SINs, combined) showed significantly longer latencies than transient cells (median for sustained cells: $34.32 \mathrm{~ms}, n=35$; median for transient cells: $28.68 \mathrm{~ms}, n=44, p=$ $0.012, \mathrm{~K}-\mathrm{S}$ test, Fig. 10). Within each cell type group, sustained simple cells showed significantly longer latencies than transient simple cells (median for 27 sustained simple cells: $37.49 \mathrm{~ms}$; median for 19 transient simple cells: $29.67 \mathrm{~ms}, p=0.017, \mathrm{~K}-\mathrm{S}$ test, Fig. 10 inset, left), while this difference was not significant in SINs (median for 8 sustained SINs: $28.58 \mathrm{~ms}$; median for 25 transient SINs: $27.10 \mathrm{~ms}$, $p=0.191, \mathrm{~K}-\mathrm{S}$ test, Fig. 10 inset, right).

\section{Spatial and temporal frequency tuning}

We did not find any significant differences in spatial and temporal tuning properties between sustained and transient simple cells (sustained vs transient, peak spatial frequency: $0.228 \pm 0.039 \mathrm{cpd}$ vs $0.176 \pm 0.024 \mathrm{cpd}, p=0.394$; spatial bandwidth: $0.670 \pm 0.080$ oct vs $0.598 \pm 0.107$ oct, $p=0.607$; peak temporal frequency: $5.979 \pm 0.875 \mathrm{~Hz}$ vs $6.644 \pm 1.156 \mathrm{~Hz}, p=0.644$; temporal bandwidth: $2.836 \pm 0.215$ oct vs $3.091 \pm 0.392$ oct, $p=0.540$ ), or 
between sustained and transient SINs (sustained vs transient, peak spatial frequency: $0.128 \pm 0.036$ cpd vs $0.241 \pm$ $0.061 \mathrm{cpd}, p=0.126$; spatial bandwidth: $1.180 \pm 0.232$ oct vs $1.201 \pm 0.119$ oct, $p=0.935$; peak temporal frequency: $5.171 \pm 2.006 \mathrm{~Hz}$ vs $6.618 \pm 1.145 \mathrm{~Hz}$, $p=0.534$; temporal bandwidth: $5.503 \pm$ 0.764 oct vs $4.430 \pm 0.513$ oct, $p=0.290$ ). Therefore, in the following analyses we grouped sustained and transient cells together and only looked for simple/SIN differences. The spatial frequency tuning was measured in 44 simple cells and 28 SINs. Each cell class showed considerably diversity in both the peak spatial frequency and the bandwidth, as illustrated in Figure $11 A$ (left) for three simple cells, one of which was low-pass (top) and the other two that were bandpass (middle and bottom). Figure $11 A$ (right) shows spatial frequency tuning curves from three SINs, within which one was bandpass (top) and the other two that were low-pass (middle and bottom). The peak spatial frequency did not differ between simple cells $(0.198 \pm 0.024 \mathrm{cpd})$ and SINs $(0.217 \pm$ 0.049 cpd, $p=0.730$, Fig. $11 B$ ). However, SINs showed a significantly wider spatial frequency tuning (SF_width: $1.197 \pm$ 0.104 oct) than simple cells (SF_width: $0.711 \pm 0.066$ oct, $p<0.001$, Fig. 11C). Within the 44 simple cells studied, 11 (25\%) were classified as low-pass and 33 (75\%) as bandpass. Within the 28 SINs, 19 $(67.86 \%)$ were classified as low-pass and 9 $(32.14 \%)$ as bandpass. Therefore, the SINs were statistically more likely to be low-pass than simple cells $\left(X^{2}\right.$ test, $X^{2}=$ $12.93, p<0.001)$. Interestingly, S2 simple cells showed significantly narrower spatial frequency tuning ( 22 vs S1: $0.433 \pm 0.057$ oct $n=4$ vs $0.739 \pm 0.071$ oct $n=40, p=$ 0.004 ) than S1 simple cells and all S2 simple cells tested for spatial frequency tuning $(n=$ 4) were bandpass. S2 simple cells also showed higher spatial frequency peaks than S1 simple cells, but this difference was not significant (S2 vs S1: $0.323 \pm 0.066 \mathrm{cpd}$ vs $0.185 \pm 0.025 \mathrm{cpd}, p=0.108)$.

The temporal frequency tuning was measured in 50 simple cells and 28 SINs, as illustrated in Figure $11 D$ for three simple cells (left) and three SINs (right). There was no significant difference in peak temporal frequency between simple cells $(5.579 \pm 0.566 \mathrm{~Hz})$ and SINs $(6.257 \pm 0.983 \mathrm{~Hz}, p=0.626$, Fig. $11 E)$. However, SINs showed significantly wider temporal frequency tuning width $(4.698 \pm 0.432$ oct) than simple cells $(2.873 \pm 0.171$ oct, $p=0.004$, Fig. $11 F)$. No significant differences in temporal frequency tuning were found between S1 and S2 simple cells.

Thus, although simple cells and SINs did not differ on preferred spatial and temporal frequencies, SINs responded to a broader range of spatial and temporal frequencies than simple cells.

A
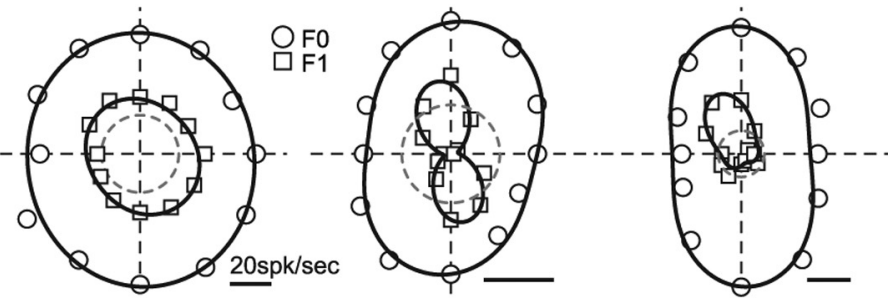

$$
\begin{array}{ll}
F 0 & F 1 \\
0.08 & 0.11 \\
0.05 & 0.06 \\
0.97 & 0.96
\end{array}
$$

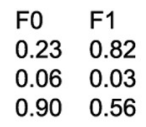

$\begin{array}{ll}\text { F0 } & \text { F1 } \\ 0.32 & 0.55 \\ 0.02 & 0.73 \\ 0.84 & 0.82\end{array}$

B
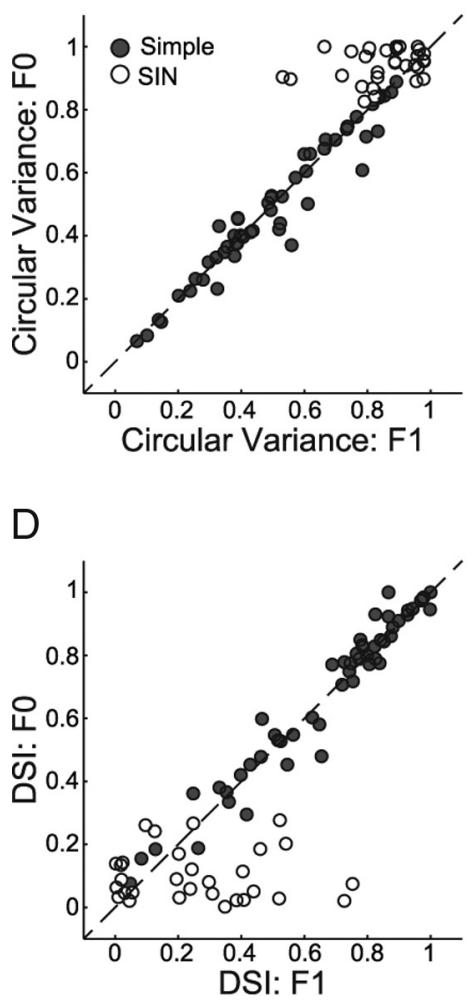

C
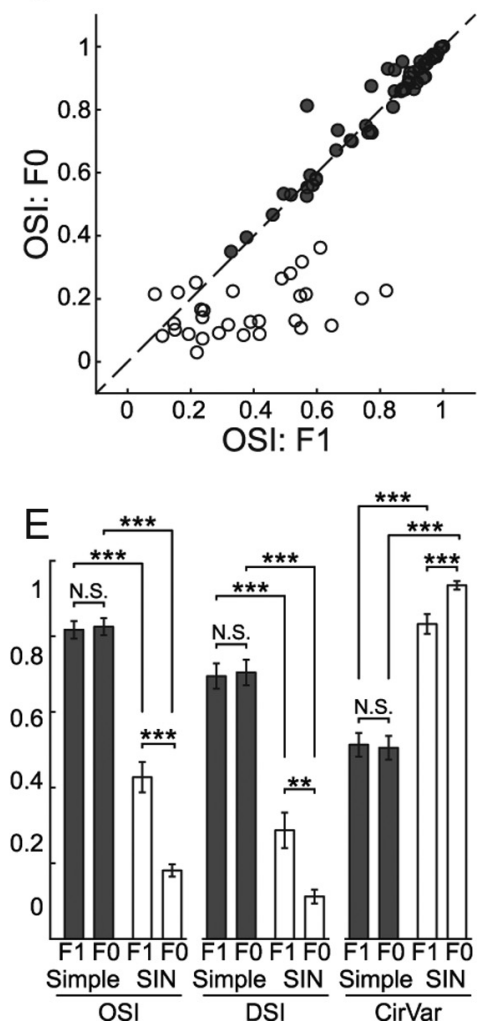

Figure 7. F1 responses of SINs are more orientation/direction selective than their F0 responses. $A$, Orientation tuning curves of F0 and F1 responses from three SINs. Gray dashed lines indicate spontaneous activity level. Note that all three SINs show F0 responses with poor orientation/direction selectivity, however, their $\mathrm{F} 1$ response could be unselective (left), orientation selective (middle), or direction selective (right). $\boldsymbol{B}-\boldsymbol{D}$, Scatter plot of orientation tuning parameters of F1 responses against those from F0 F1 responses and between simple cells and SINs. F1 vs F0: paired $t$ test. Simple vs SIN: independent $t$ test. ${ }^{* *} p<0.01$; ${ }^{* * *} p<$ 0.001 . N.S., Not significant, $p>0.05$.

Drifting gratings for SINs were optimized based on their F0 responses because the F1 responses were usually small and noisy. However, some SINs had robust F1 responses that were well fitted to our temporal and/or spatial frequency models (goodness of fitting, $R^{2}>0.8$ ). In these SINs, we measured the tuning parameters for both F1 and F0 responses and, as we found for orientation selectivity (Fig. 7), the widths of their spatial and temporal frequency tuning were significantly smaller when measured with $\mathrm{F} 1$ responses than with $\mathrm{F} 0$ responses (paired $t$ test, $\mathrm{F} 1$ vs $\mathrm{F} 0, \mathrm{SF}$ width: $1.160 \pm 0.078$ oct vs $1.420 \pm 0.098$ oct, $p=0.029, n=19$; TF width: $2.868 \pm 0.336$ oct vs $3.711 \pm 0.288$ oct, $p=0.049, n=$ 21). No significant differences were seen in spatial and temporal frequency peaks between $\mathrm{F} 1$ and $\mathrm{F} 0$ responses of SINs (paired $t$ test, F1 vs F0, SF peak: $0.055 \pm 0.011 \mathrm{cpd}$ vs $0.143 \pm 0.042 \mathrm{cpd}$, 

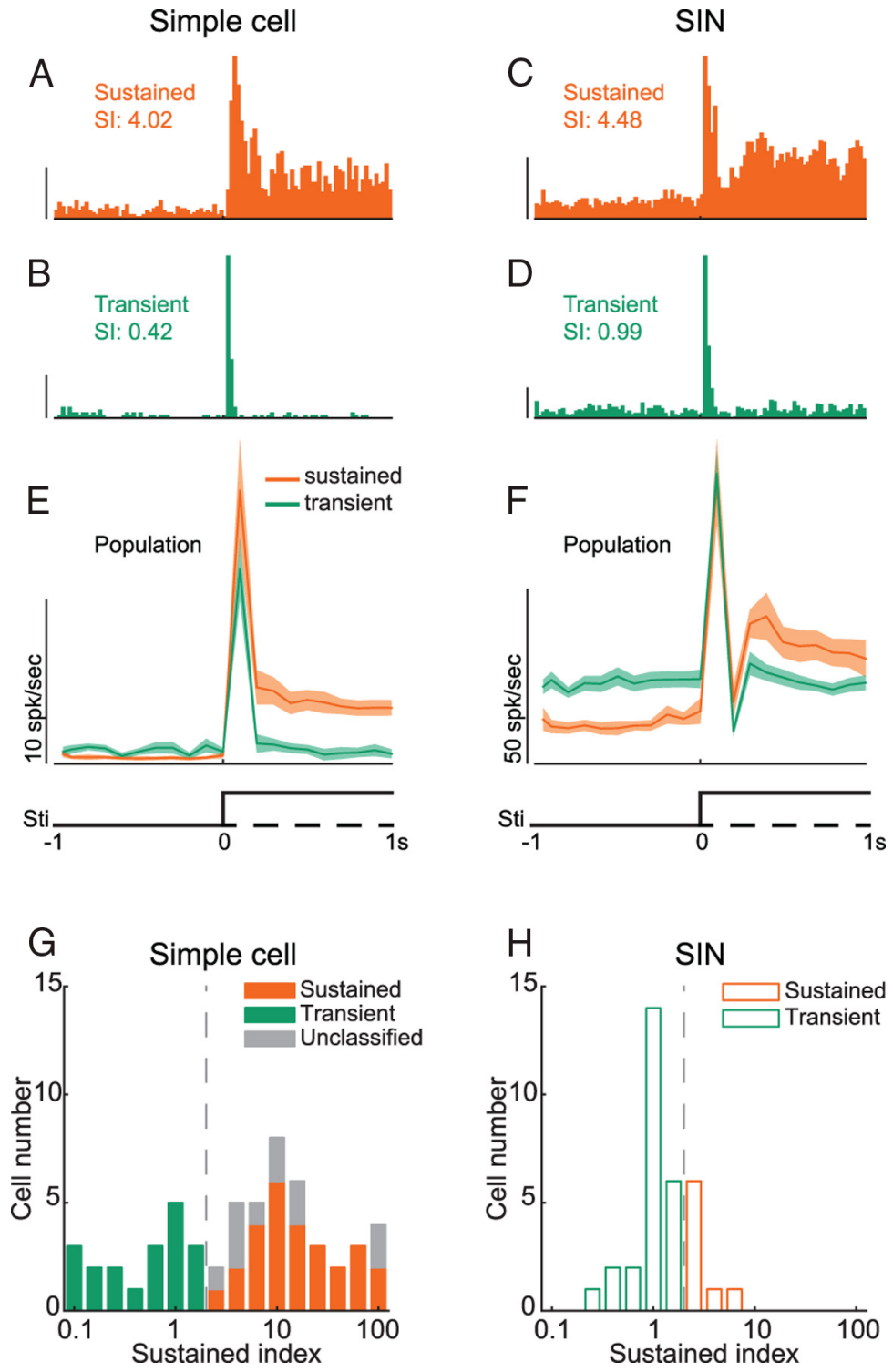

Figure 8. Sustained/transient responses of simple cells and SINs. A-D, Response PSTHs to stationary flashing visual stimuli of a sustained simple cell $(\boldsymbol{A})$, a transient simple cell $(\boldsymbol{B})$, a sustained SIN $(\boldsymbol{C})$, and a transient SIN $(\boldsymbol{D})$. SIs (ratio between sustained component to baseline, see Materials and Methods) are labeled for each cell. $\boldsymbol{E}$, Population average for sustained and transient simple cells. $\boldsymbol{F}$, Population average for sustained and transient SINs. Shaded area represents mean \pm SEM for each bin. $\boldsymbol{G}$, Sustained index distribution of simple cells. $\boldsymbol{H}$, Sustained index distribution of SINs. Dashed line marks the cutoff criterion for classifying sustained and transient cells. Calibration: (in $\boldsymbol{A}, \boldsymbol{B}, \boldsymbol{E}$ ) $10 \mathrm{spk} / \mathrm{s}$; (in $\boldsymbol{C}, \boldsymbol{D}, \boldsymbol{F}$ ) $50 \mathrm{spk} / \mathrm{s}$.

$p=0.071, n=19$; TF peak: $6.776 \pm 1.112 \mathrm{~Hz}$ vs $6.967 \pm 1.109$ $\mathrm{Hz}, n=21, p=0.866)$. These results are consistent with the $\mathrm{F} 1$ and F0 differences that we report for orientation tuning and demonstrate that the F0 responses of SINs are less selective than their F1 responses.

\section{Simple cells with brief spikes have properties like other simple cells, not like SINs}

As mentioned above, some of simple cells in this study had short duration spikes (Fig. 1B) that were indistinguishable from those of most SINs. It is interesting to ask if such cells behaved, in other respects, like simple cells, or like the SINs of our study. To answer this, we examined the response properties of all simple cells with spike durations of $<0.7 \mathrm{~ms}(n=8)$. We found that these eight simple cells responded to electrical stimulation of the thalamus in a manner characteristic of other simple cells, not of SINs. Thus, none had latencies (Fig. 1B) of $<2 \mathrm{~ms}$. Three of these cells did not respond to thalamic stimulation, and the remaining five had latencies of $2.0-4.0 \mathrm{~ms}$ (mean $=3.1$ $\mathrm{ms}$ ). In addition, only one of these eight cells responded to thalamic stimulation with more than a single spike (this cell responded with two spikes, with a minimal interspike interval of $2.0 \mathrm{~ms}$ ). Thus, these eight simple cells are not at all similar to SINs in their responses to thalamic stimulation. Moreover, we found that the eight simple cells with short-duration spikes were also very different from SINs (and very similar to the overall population of simple cells) in their spontaneous firing rates (ranges: $0.15-0.57 \mathrm{spk} / \mathrm{s}$ ), in their LSIs $(0-0.21)$, in their F1/F0 ratios (1.28$1.83)$, and in their OSIs $(0.52-0.97)$ and DSIs (0.46-1.0).

\section{SINs receive monosynaptic input from LGN neurons}

By definition, all SINs in the above experiments responded to thalamic electrical stimulation with at least three spikes, and most did so at short latencies (Fig. 1C). Although this is highly suggestive of monosynaptic input to SINs from LGN axons, this is not necessarily the case, as such synaptic activation could be mediated via the recurrent collaterals of antidromically activated corticothalamic axons. To investigate whether SINs do, indeed, receive monosynaptic input from LGN axon terminals, we performed cross-correlation analysis for five additional SINs that each were recorded simultaneously with at least one LGN neuron that was in precise retinotopic alignment (Reid and Alonso, 1995; Alonso et al., 2001; Swadlow and Gusev, 2001, 2002). We found that each of the five SINs did, indeed, show clear evidence of monosynaptic input from at least one LGN cell, showing a sharp, brief increase in SIN spike probability at a short latency (onset latency: 1.3-1.8 ms; peak latency: 1.5-2.1 ms) following the thalamic spike (Fig. 12). Four additional LGN neurons were retinotopically aligned with at least one of these SINs but did not make a functional connection, and one LGN cell made a functional impact on each of the two SINs that it was aligned with (notably, these two SINs had dominant ON responses, but the LGN neuron was OFF center, Fig. $12 C, D)$. However, this dataset is too small to draw conclusions about the "rules" for connectivity (Alonso and Martinez, 1998; Alonso et al., 2001; Swadlow and Gusev, 2002) between LGN cells and SINs. What is clear from these data, is that the SINs of layer 4 do, indeed, receive monosynaptic input from the LGN.

The effect of spontaneous activity on SIN response properties In the current study, we found that SINs maintained very high spontaneous activity (Fig. $4 A$ ) in the absence of visual stimulation. This could imply that the simple/SIN differences in response properties may be solely due to their very different 
spontaneous rates. Therefore, it is important to compare the RF properties between simple cells and SINs after removing their spontaneous activity. These comparisons were done on the subset of our cell populations for which we had good measures of spontaneous activity, and the main conclusions of this analysis are summarized below.

First, the maximum F0 responses from SINs were still significantly higher than those from simple cells after subtraction of spontaneous activity (maxF0-spont: 26 simple cells vs 15 SINs, $7.513 \pm 1.013 \mathrm{spk} / \mathrm{s}$ vs $31.941 \pm 3.760 \mathrm{spk} / \mathrm{s}, p<0.001$; Fig. $4 B$, inset).

Second, the F1/F0 ratios of simple cells and SINs measured without spontaneous activity [calculated through rectifying PSTHs by spontaneous firing rate (Chen et al., 2009)] were significantly different (F1/F0 rectified, 36 simple cells vs 15 SINs, $1.632 \pm 0.046$ vs $0.863 \pm 0.140, p<$ $0.001)$, but the distribution did not appear bimodal (Hartigan's test, $p=0.975$; Fig. $4 D$, inset). After removing spontaneous activity, $96 \%$ (25 of 26) of simple cells had F1/F0 ratios $>1$ while only $46 \%$ (7 of 15 ) of SINs had F1/F0 ratios $>1$. This difference between simple cells and SINs, while highly significant, is not as prominent as that seen when spontaneous activity is included, indicating that the spontaneous activity does affect the F1/F0 calculation for SINs.

Third, subtracting spontaneous activity from F0 did not affect simple/SIN difference on orientation tuning (F0spontaneous activity, 28 simple cells vs 15 SINs, OSI: $0.872 \pm 0.037$ vs $0.406 \pm 0.070$, $p<0.001$; DSI: $0.768 \pm 0.052$ vs $0.159 \pm$ $0.032, p<0.001$; CirVar: $0.413 \pm 0.053$ vs $0.786 \pm 0.062, p<0.001)$, and bimodal distributions were still found in DSI and circular variance (Hartigan's test, OSI: $p=0.311$; DSI: $p=0.003$; CirVar: $p=$ $0.043)$. However, the orientation selectivity differences between F1 and F0 responses of SINs (Fig. 7) were reduced by subtracting spontaneous activity from $\mathrm{F} 0$ responses (paired $t$ test, 14 SINs, F1 vs F0spont, OSI: $0.470 \pm 0.055$ vs 0.388 vs $0.072, p=0.270$; DSI: $0.307 \pm 0.059$ vs $0.167 \pm 0.034, p<0.001$; CirVar: $0.809 \pm$ 0.039 vs $0.794 \pm 0.066, p=0.836$ ).

Finally, the measurements of C50 from the contrast response function, temporal/spatial frequency peak, and temporal/spatial frequency tuning width were independent from baseline measurements (see Materials and Methods). Therefore, the subtraction of spontaneous activity does not affect the values of these parameters. In summary, these results indicate that removing the spontaneous activity from F0 responses affect the calculation of some RF properties for SINs, however, the main differences be-
Simple cell
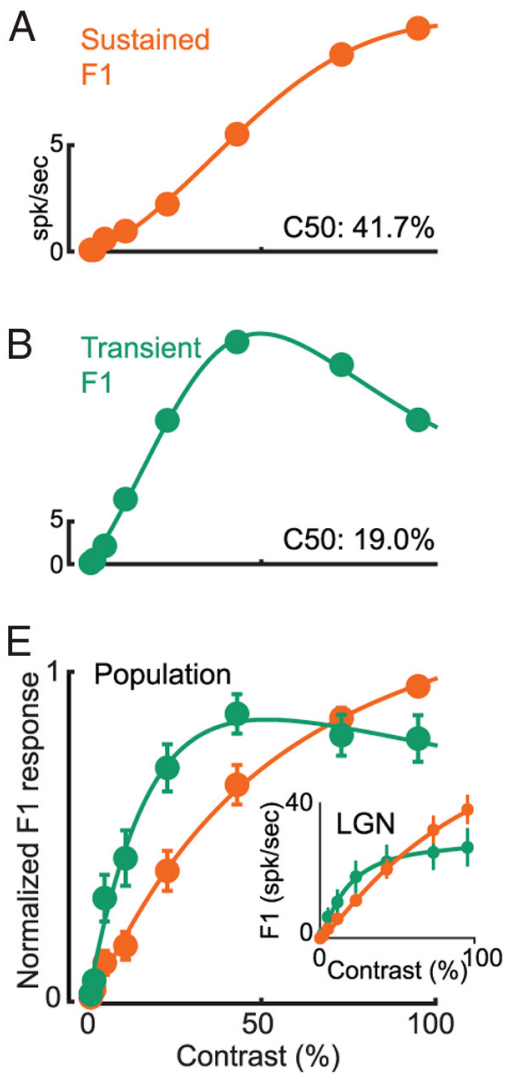

G

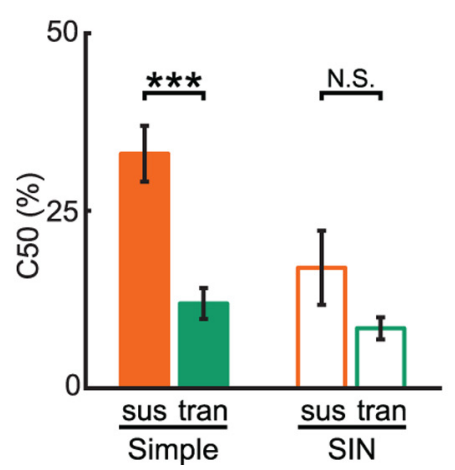

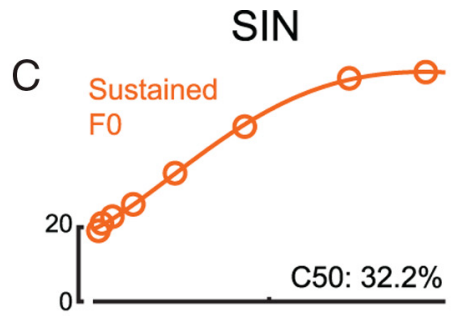
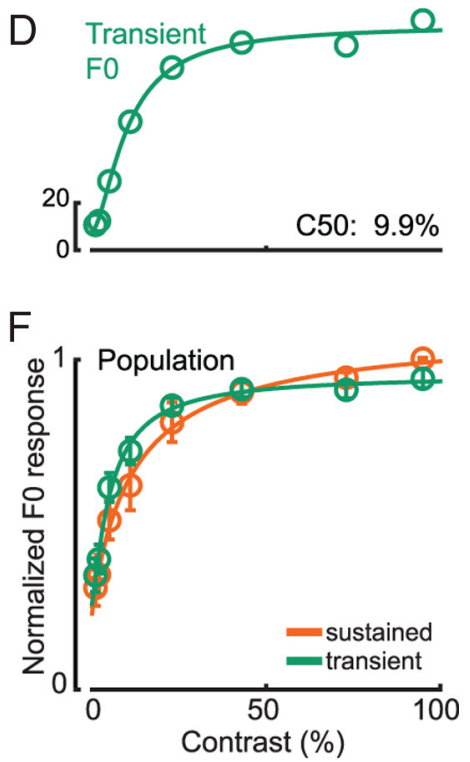

Figure 9. Contrast response properties of sustained and transient cells for both simple cells and SINs. $A-D$, Contrast response functions of the same cells plotted in Figure $8 A-D$, respectively. Raw data were fitted by hyperbolic function (see Materials and Methods). (50s are labeled for each cell. $\boldsymbol{E}$, Normalized population average contrast response function of sustained and transient simple cells. Inset, Population average contrast response functions of sustained and transient LGN cells [modified from the study by Cano et al. (2006) with permission]. $\boldsymbol{F}$, Normalized population average contrast response functions of sustained and transient SINs. $\mathbf{G}$, Comparison of C50s from these four cell groups (sustained simple cells, transient simple cell, sustained SIN, and transient SIN). Sustained vs transient: independent $t$ test. ${ }^{* * *} p<0.001$. N.S., No significance, $p>0.05$. $\boldsymbol{H}$, Percentage of cells showing high-contrast suppression within each of these four cell groups.

tween SINs and simple cells that we report can still be demonstrated.

\section{Discussion}

Identification of layer 4 SINs and simple cells

SINs were identified by high-frequency $(>600 \mathrm{~Hz})$ discharge of $3+$ spikes following thalamic stimulation, and simple cells were identified solely by their RF properties, requiring spatially discrete $\mathrm{ON}$ and/or OFF subregions. Notably, no neuron met both 


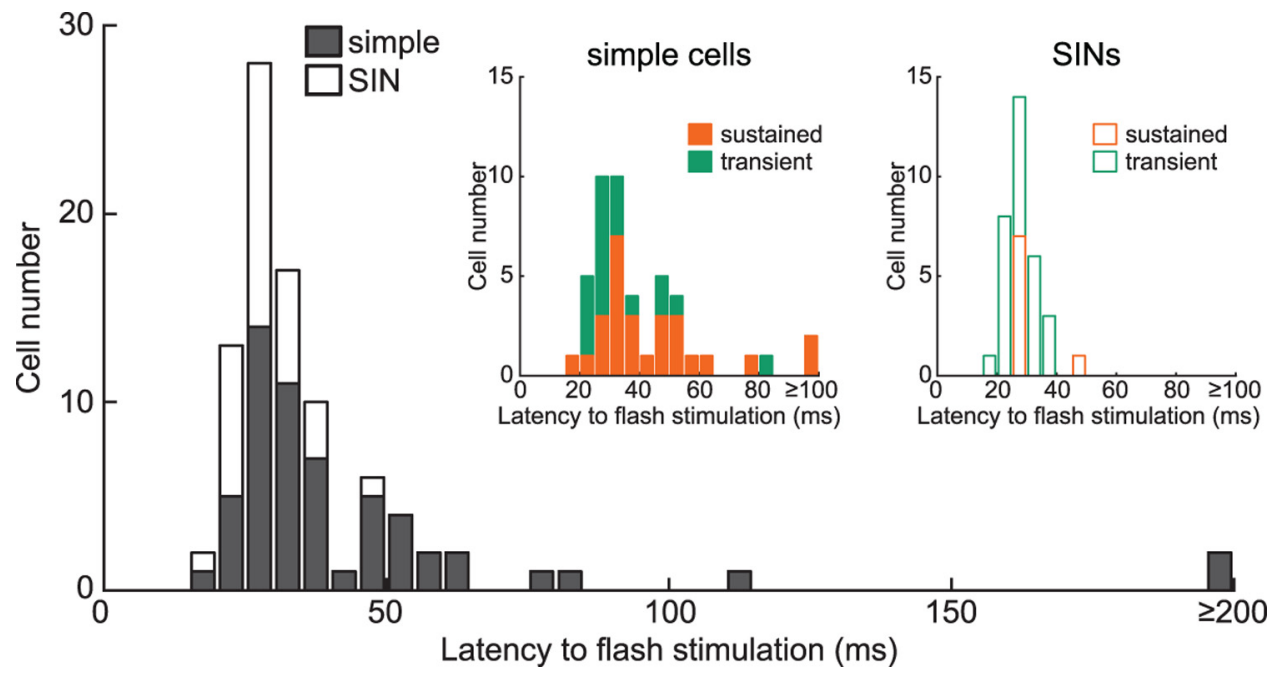

Figure 10. Distribution of latencies to flash visual stimulation of simple cells and SINs. Inset, Distribution broken down into sustained/transient groups for simple cells and SINs.
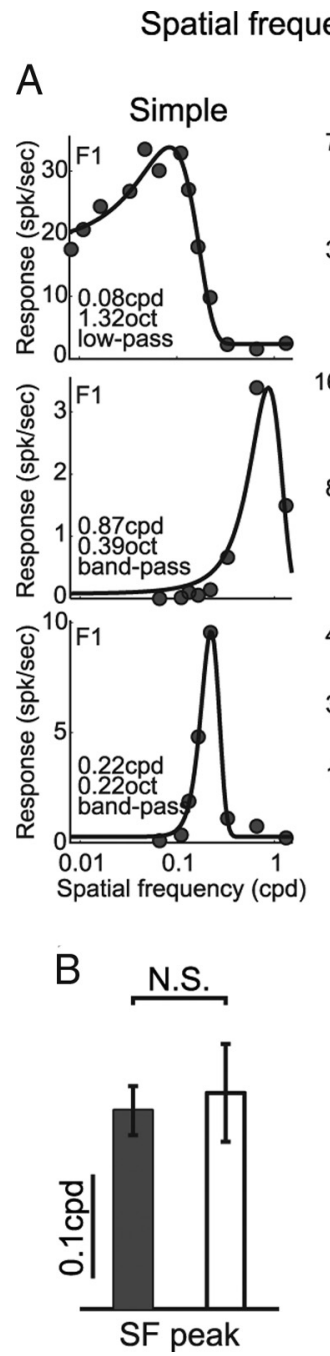

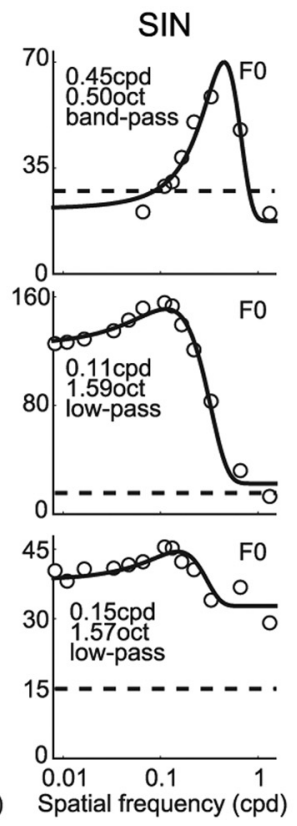

C

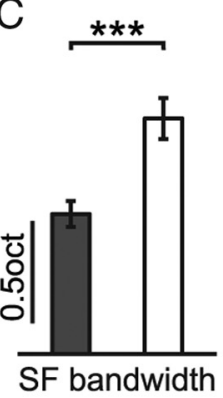

Temporal frequency tuning
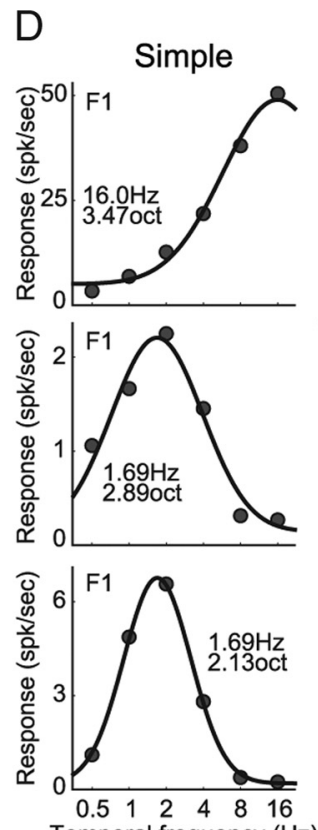

Temporal frequency $(\mathrm{Hz})$ Temporal frequency $(\mathrm{Hz})$

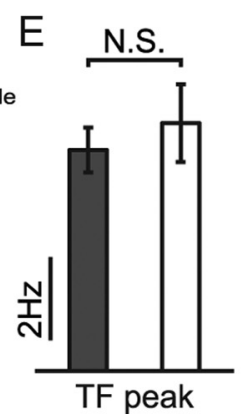

$\mathrm{F}$
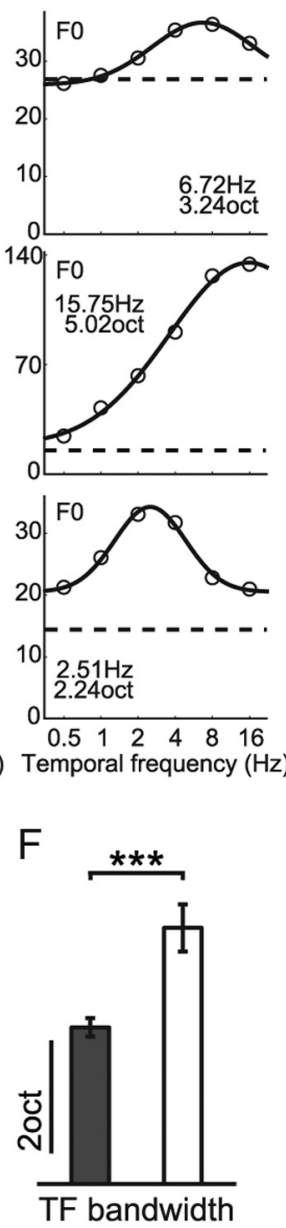

Figure 11. Spatial and temporal frequency tuning properties of simple cells and SINs. A, Spatial frequency tunings of three simple cells and three SINs. Raw data were fitted by Gaussian function. Peak spatial frequency, tuning bandwidth, and pass mode (low-pass/bandpass) are labeled for each cell. B, C, Comparison of peak spatial frequency and spatial frequency tuning bandwidth between simple cells and SINs, respectively. D, Temporal frequency tunings of the same three simple cells and three SINs. Raw data were fitted by Gaussian function on logarithmic scale. Peak temporal frequency and temporal frequency tuning bandwidth are labeled for each cell. $\boldsymbol{E}-\boldsymbol{F}$, Comparison of peak temporal frequency and temporal frequency tuning bandwidth between simple cells and SINs, respectively. Dashed lines indicate spontaneous activity levels for SINs. Simple vs SIN: independent $t$ test. N.S., No significance, $p>0.05 .{ }^{* * *} p<0.001$. 

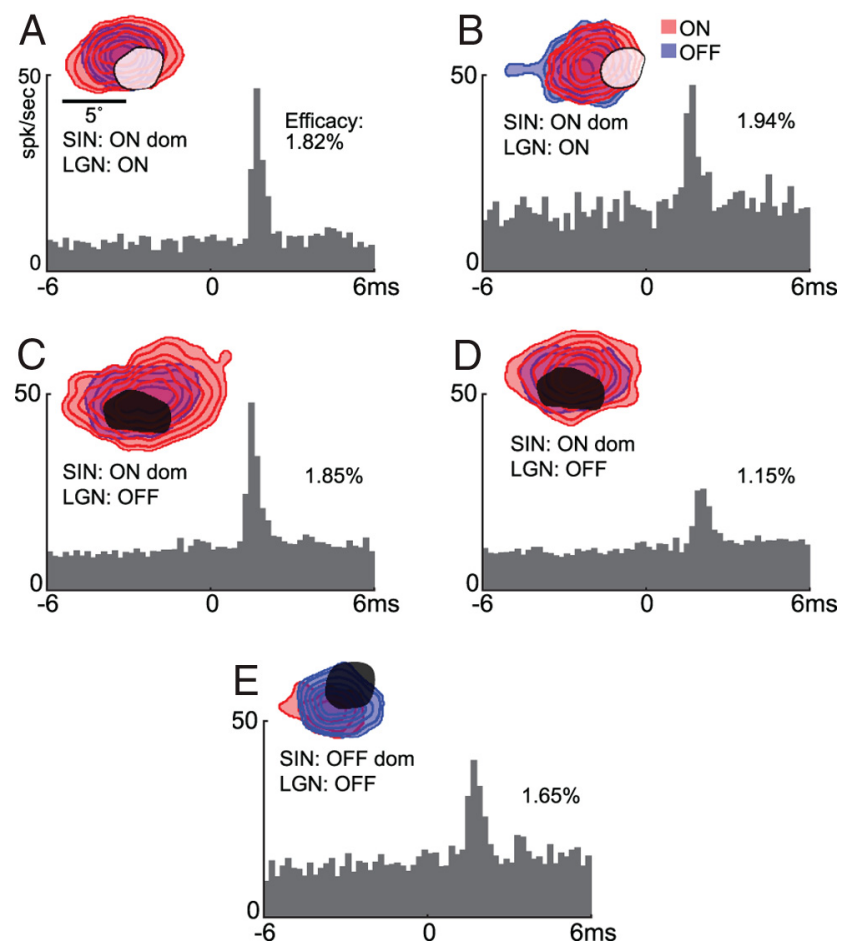

Figure 12. Layer 4 SINs receive monosynaptic thalamocortical inputs. $A-E$, Crosscorrelograms of five simultaneously recorded cell pairs between retinotopically aligned LGN cells and layer 4 SINs. The $x$-axis represents the relative timing to LGN spikes. Efficacy of each connection is shown for each crosscorrelogram. Insets, The RF maps of LGN cells and SINs. Red/blue, ON/OFF subfield of SINs, respectively. ON or OFF dominancy was labeled for each SIN. White/black patches, RF of ON/OFF centered LGN cells, respectively. Note that in $\boldsymbol{C}$ and $\boldsymbol{D}$, a single LGN OFF-center cell contracted two layer 4 SINs, each with an $0 \mathrm{~N}$-dominated receptive fields.

criteria. All SINs had overlapping ON/ OFF subfields, and most simple cells responded with only one spike to thalamic stimulation. Moreover, SINs had much shorter latencies and minimal interspike intervals to thalamic stimulation than simple cells (Fig. $1 C, D)$, and threshold intensities were much lower (see Results). Such responsiveness of SINs to thalamic (and visual, Fig. 4) stimulation, probably reflect a combination of factors, including membrane properties (Azouz et al., 1997; Cardin et al., 2007), large unitary thalamocortical EPSPs (Gibson et al., 1999; Gabernet et al., 2005; Cruikshank et al., 2007; Hull et al., 2009; Cruikshank et al., 2010; Bagnall et al., 2011), and extensive thalamocortical convergence onto SINs (Swadlow and Gusev, 2002) (see below).

Although not used as an identification criterion, SINs had shorter-duration spikes than simple cells. However, there was overlap in these distributions (Fig. $1 B$ ). We have emphasized the need for criteria other than spike duration for extracellular identification of fast spike GABAergic interneurons (Swadlow, 2003). Notably, some spiny neurons, including identified projection neurons of sensory (Dykes et al., 1988; Swadlow, 1989, 1990) and motor (Takahashi, 1965) cortices, and "chattering" cells (Gray and McCormick, 1996) have short-duration spikes. Because of this and because the few simple cells with short-duration spikes were, in all other ways, similar to other simple cells, not SINs, we think it very unlikely that they were fast spike GABAergic interneurons. However, some simple cells could have been GABAergic interneurons of other classes (e.g., somatostatin positive interneurons), which have longer-duration spikes and receptive fields and other properties distinct from those of fast spike
Table 3. Comparison of contrast responses between sustained and transient groups for both layer 4 simple cells and SINs

\begin{tabular}{|c|c|c|c|c|}
\hline & \multicolumn{2}{|c|}{ Layer 4 simple cells } & \multicolumn{2}{|l|}{ Layer 4 SINs } \\
\hline & Sustained & Transient & Sustained & Transient \\
\hline $\mathrm{C} 50(\%)$ & $33.04 \pm 3.94$ & $11.93 \pm 2.17^{* * *}$ & $16.97 \pm 5.22$ & $8.44 \pm 1.56^{\text {N.S. }}$ \\
\hline $\begin{array}{l}\% \text { of cells with high } \\
\text { contrast suppression }\end{array}$ & $28.6 \%$ & $50 \%$ & $28.6 \%$ & $33.3 \%$ \\
\hline
\end{tabular}

parvalbumin-positive interneurons (Gibson et al., 1999; Ma et al., 2010; Adesnik et al., 2012).

\section{Response properties of layer 4 simple cells and SINs}

Although simple cells were required to have spatially separate $\mathrm{ON}$ and/or OFF subfields, there were no receptive field requirements for SINs. Nevertheless, ON/OFF subfield separation (LSI) of simple cells and SINs was strongly bimodal and subfield sizes (width, area) were much smaller in simple cells than SINs (Fig. 3B-D).

SINs had much higher spontaneous firing rates than simple cells and the distribution was strongly bimodal (Fig. 4A). The high firing rates of SINs is consistent with results in awake mouse (Niell and Stryker, 2010), and results in other layers of awake rabbit V1 (Swadlow, 1988), S1 (Swadlow, 1989, 1990), S2 (Swadlow, 1991), and motor cortex (Swadlow, 1994), where SINs have the highest spontaneous firing rates. SINs also had higher F0 and F1 responses than simple cells (Fig. $4 B, C$ ), but responded with similar reliability (Fig. 4E).

The F1/F0 ratio is often used to define simple versus complex V1 neurons, with ratios of $>1$ used to classify "linear" simple cells, and those $<1$ to classify "nonlinear" complex cells (Skottun et al., 1991). We found that F1/F0 ratios were $<1$ for all SINs and $>1$ for nearly all simple cells (54/57, Fig. 4D). However, when spontaneous firing rates were subtracted from F0 responses (Fig. $4 D$, inset), the distinction between these populations was less categorical, although still highly significant.

Simple cells displayed considerable orientation selectivity (and often directional selectivity) in their F0 and F1 responses (Figs. 6, 7). By contrast, SINs were broadly tuned to orientation/ direction in their F0 responses (Fig. 6). Interestingly, the relatively small F1 responses of SINs were sometimes more orientation/direction selective than the much larger F0 responses (Fig. 7). Nevertheless, across multiple comparisons, SINs were far less selective for orientation/direction than simple cells.

V1 simple cells similar to those reported here are found in rats (Girman et al., 1999), mice (Niell and Stryker, 2008; Liu et al., 2009), squirrels (Heimel et al., 2005; Van Hooser et al., 2005), and in other layers of rabbit V1 (Swadlow and Weyand, 1987; Swadlow, 1988). Notably, orientation selectivity of V1 simple cells can be very sharp, despite the lack of orientation columns (Ohki and Reid, 2007). Similarly, high spontaneous firing rates, low (nonlinear) F1/F0 ratios, spatially overlapping ON/OFF RF subfields, and broad orientation/direction tuning occur in putative fast spike interneurons in layer 4 of anesthetized mice (Niell and Stryker, 2008; Liu et al., 2009), and broad orientation tuning is seen in parvalbumin-positive neurons in layer 2-3 of mouse (Kerlin et al., 2010; but see Runyan et al., 2010) and in SINs of superficial and deep layers of awake rabbit (Swadlow and Weyand, 1987; Swadlow, 1988). In cat V1, however, some fast-spiking GABAergic interneurons have sharp orientation tuning, display spatially separate ON/OFF subfields or F1/F0 ratios indicative of simple cells (Azouz et al., 1997; Hirsch et al., 2003; Cardin et al., 2007; Nowak et al., 2008). Thus, differences in the complexity of 
visual processing seen in different mammalian lines may be reflected by corresponding differences in the diversity of interneuron response properties.

\section{The sustained/transient distinction in layer 4 simple cells and SINs}

LGN concentric neurons can be classified as sustained or transient, based on response to maintained stimulation of the RF center (Cleland et al., 1971). In LGN of awake rabbits, the distribution of response duration to sustained stimulation is bimodal (Swadlow and Weyand, 1985; Bezdudnaya et al., 2006; Stoelzel et al., 2008). Notably, transient cells are much more sensitive to low contrast than sustained cells (Cano et al., 2006), similar to differences between transient magnocellular and sustained parvocellular LGN cells in new world primates (Usrey and Reid, 2000). Here, although many simple cells and SINs could be clearly classified as sustained or transient, some were ambiguous and the distinction was not as clear as in LGN. Nevertheless, transient simple cells were much more sensitive to low contrasts than sustained simple cells, and suppressed their responses more strongly at high contrasts (Table 3). A similar pattern was seen in rabbit LGN transient cells, but high-contrast suppression seems to originate in V1 (Fig. 9E, inset).

\section{SINs as conveyers of broadly tuned inhibition}

Theoretical studies suggest that a broadly tuned suppression, generated within the local microcircuit, may sharpen the tuning properties of recipient spiny neurons, and control gain (Heeger, 1992; Troyer et al., 1998; McLaughlin et al., 2000), and these ideas have received experimental support (Carandini et al., 1997; Xing et al., 2011; Shapley and Xing, 2013). The receptive fields of most layer 4 excitatory cells in mouse V1 consist of only one subfield that is sharply tuned for orientation (Niell and Stryker, 2008; Liu et al., 2009) (as we reported here in rabbit V1). Recent work on mice has shown that broadly tuned inhibition is important in sharpening orientation selectivity of such cells (Liu et al., 2011). Furthermore, activation of cortical parvalbumin-positive GABAergic cells sharpens the orientation selectivity of excitatory cells (Lee et al., 2012; but see Wilson et al., 2012). Consistent with these findings, the fast and strong feedforward response of SINs, and their broad orientation, spatial, and temporal tuning, make them well suited to convey a fast, broadly tuned inhibition onto local spiny neurons.

\section{Thalamocortical specificity and mechanisms underlying diverse response properties of layer 4 populations}

Separate ON/OFF subregions of V1 simple cells (and orientation preferences) are thought to originate from selective thalamocortical inputs with ON or OFF RF centers precisely aligned with the cortical RF subfields (Hubel and Wiesel, 1962; Tanaka, 1983; Reid and Alonso, 1995; Alonso et al., 2001) (but see Mata and Ringach, 2005). By contrast, a promiscuous, unselective thalamocortical input would be expected to generate RFs with ON/OFF spatial overlap and poor orientation selectivity (Alonso and Swadlow, 2005). A promiscuous, unselective thalamocortical functional connectivity has been demonstrated in somatosensory cortex of rats and rabbits, where layer 4 SINs (Swadlow, 1995; Swadlow and Gusev, 2002) or fast spike cells (Bruno and Simons, 2002) receive potent inputs from a large proportion of topographically aligned thalamocortical neurons (Sun et al., 2006) (also see Inoue and Imoto, 2006). In these systems, most somatosensory thalamocortical neurons are sharply tuned for whisker deflection direction, and many such neurons (with a diversity of directional preferences) converge upon individual SINs/fast spike cells, which show minimal directional tuning. Notably, SINs of rabbit somatosensory cortex, like those of $\mathrm{V} 1$, respond at very short latency to peripheral stimulation (Swadlow, 1995). In the visual thalamocortical system, a similar unselective input from ON-center and OFF-center LGN neurons could generate the overlapping ON/ OFF RFs seen in V1 SINs, and our data provide examples of an OFF-center LGN neuron providing input to SINs with ONdominated RFs (Fig. 12C,D). We suggest that a promiscuous thalamocortical input onto fast spike interneurons of layer 4 may be a general feature of sensory neocortex. This, together with a highly convergent input from other cortical neurons (Bock et al., 2011) and the electrical coupling observed among neighboring fast spike interneurons (Gibson et al., 1999, 2005; Galarreta and Hestrin, 2002) may account for the high responsiveness and broad tuning of these cells to many aspects of sensory stimulation.

\section{References}

Adesnik H, Bruns W, Taniguchi H, Huang ZJ, Scanziani M (2012) A neural circuit for spatial summation in visual cortex. Nature 490:226-231. CrossRef Medline

Albrecht DG, Hamilton DB (1982) Striate cortex of monkey and cat: contrast response function. J Neurophysiol 48:217-237. Medline

Alitto HJ, Moore BD 4th, Rathbun DL, Usrey WM (2011) A comparison of visual responses in the lateral geniculate nucleus of alert and anaesthetized macaque monkeys. J Physiol 589:87-99. CrossRef Medline

Alonso JM, Martinez LM (1998) Functional connectivity between simple cells and complex cells in cat striate cortex. Nat Neurosci 1:395-403. CrossRef Medline

Alonso JM, Swadlow HA (2005) Thalamocortical specificity and the synthesis of sensory cortical receptive fields. J Neurophysiol 94:26-32. CrossRef Medline

Alonso JM, Usrey WM, Reid RC (2001) Rules of connectivity between geniculate cells and simple cells in cat primary visual cortex. J Neurosci 21:4002-4015. Medline

Asher RJ, Bennett N, Lehmann T (2009) The new framework for understanding placental mammal evolution. Bioessays 31:853-864. CrossRef Medline

Azouz R, Gray CM, Nowak LG, McCormick DA (1997) Physiological properties of inhibitory interneurons in cat striate cortex. Cereb Cortex 7:534545. CrossRef Medline

Bagnall MW, Hull C, Bushong EA, Ellisman MH, Scanziani M (2011) Multiple clusters of release sites formed by individual thalamic afferents onto cortical interneurons ensure reliable transmission. Neuron 71:180-194. CrossRef Medline

Bereshpolova Y, Amitai Y, Gusev AG, Stoelzel CR, Swadlow HA (2007) Dendritic backpropagation and the state of the awake neocortex. J Neurosci 27:9392-9399. CrossRef Medline

Bereshpolova Y, Stoelzel CR, Zhuang J, Amitai Y, Alonso JM, Swadlow HA (2011) Getting drowsy? Alert/nonalert transitions and visual thalamocortical network dynamics. J Neurosci 31:17480-17487. CrossRef Medline

Bezdudnaya T, Cano M, Bereshpolova Y, Stoelzel CR, Alonso JM, Swadlow HA (2006) Thalamic burst mode and inattention in the awake LGNd. Neuron 49:421-432. CrossRef Medline

Bock DD, Lee WC, Kerlin AM, Andermann ML, Hood G, Wetzel AW, Yurgenson S, Soucy ER, Kim HS, Reid RC (2011) Network anatomy and in vivo physiology of visual cortical neurons. Nature 471:177-182. CrossRef Medline

Bousfield JD (1977) Columnar organisation and the visual cortex of the rabbit. Brain Res 136:154-158. CrossRef Medline

Bruno RM, Simons DJ (2002) Feedforward mechanisms of excitatory and inhibitory cortical receptive fields. J Neurosci 22:10966-10975. Medline

Cano M, Bezdudnaya T, Swadlow HA, Alonso JM (2006) Brain state and contrast sensitivity in the awake visual thalamus. Nat Neurosci 9:12401242. CrossRef Medline

Carandini M, Heeger DJ, Movshon JA (1997) Linearity and normalization in simple cells of the macaque primary visual cortex. J Neurosci 17:86218644. Medline

Cardin JA, Palmer LA, Contreras D (2007) Stimulus feature selectivity in excitatory and inhibitory neurons in primary visual cortex. J Neurosci 27:10333-10344. CrossRef Medline 
Chen Y, Anand S, Martinez-Conde S, Macknik SL, Bereshpolova Y, Swadlow HA, Alonso JM (2009) The linearity and selectivity of neuronal responses in awake visual cortex. J Vis. 9:12.11-17. Medline

Cleland BG, Dubin MW, Levick WR (1971) Sustained and transient neurones in the cat's retina and lateral geniculate nucleus. J Physiol 217:473496. Medline

Collewijn H (1971) The optokinetic system of the rabbit. Doc Ophthalmol 30:205-226. CrossRef Medline

Contreras D, Palmer L (2003) Response to contrast of electrophysiologically defined cell classes in primary visual cortex. J Neurosci 23:6936-6945. Medline

Cruikshank SJ, Lewis TJ, Connors BW (2007) Synaptic basis for intense thalamocortical activation of feedforward inhibitory cells in neocortex. Nat Neurosci 10:462-468. Medline

Cruikshank SJ, Urabe H, Nurmikko AV, Connors BW (2010) Pathwayspecific feedforward circuits between thalamus and neocortex revealed by selective optical stimulation of axons. Neuron 65:230-245. CrossRef Medline

DeAngelis GC, Ghose GM, Ohzawa I, Freeman RD (1999) Functional micro-organization of primary visual cortex: receptive field analysis of nearby neurons. J Neurosci 19:4046-4064. Medline

Dykes RW, Lamour Y, Diadori P, Landry P, Dutar P (1988) Somatosensory cortical neurons with an identifiable electrophysiological signature. Brain Res 441:48-58. CrossRef Medline

Fuller JH (1981) Eye and head movements during vestibular stimulation in the alert rabbit. Brain Res 205:363-381. CrossRef Medline

Gabernet L, Jadhav SP, Feldman DE, Carandini M, Scanziani M (2005) Somatosensory integration controlled by dynamic thalamocortical feedforward inhibition. Neuron 48:315-327. CrossRef Medline

Galarreta M, Hestrin S (2002) Electrical and chemical synapses among parvalbumin fast-spiking GABAergic interneurons in adult mouse neocortex. Proc Natl Acad Sci U S A 99:12438-12443. CrossRef Medline

Gibson JR, Beierlein M, Connors BW (1999) Two networks of electrically coupled inhibitory neurons in neocortex. Nature 402:75-79. CrossRef Medline

Gibson JR, Beierlein M, Connors BW (2005) Functional properties of electrical synapses between inhibitory interneurons of neocortical layer 4 . J Neurophysiol 93:467-480. Medline

Girman SV, Sauv é Y, Lund RD (1999) Receptive field properties of single neurons in rat primary visual cortex. J Neurophysiol 82:301-311. Medline

Gray CM, McCormick DA (1996) Chattering cells: superficial pyramidal neurons contributing to the generation of synchronous oscillations in the visual cortex. Science 274:109-113. CrossRef Medline

Hawken MJ, Shapley RM, Grosof DH (1996) Temporal-frequency selectivity in monkey visual cortex. Vis Neurosci 13:477-492. CrossRef Medline

Heeger DJ (1992) Normalization of cell responses in cat striate cortex. Vis Neurosci 9:181-197. CrossRef Medline

Heimel JA, Van Hooser SD, Nelson SB (2005) Laminar organization of response properties in primary visual cortex of the gray squirrel (Sciurus carolinensis). J Neurophysiol 94:3538-3554. CrossRef Medline

Hirsch JA, Martinez LM (2006) Circuits that build visual cortical receptive fields. Trends Neurosci 29:30-39. CrossRef Medline

Hirsch JA, Alonso JM, Reid RC, Martinez LM (1998) Synaptic integration in striate cortical simple cells. J Neurosci 18:9517-9528. Medline

Hirsch JA, Martinez LM, Pillai C, Alonso JM, Wang Q, Sommer FT (2003) Functionally distinct inhibitory neurons at the first stage of visual cortical processing. Nat Neurosci 6:1300-1308. CrossRef Medline

Hubel DH, Wiesel TN (1962) Receptive fields, binocular interaction and functional architecture in the cat's visual cortex. J Physiol 160:106-154. Medline

Hull C, Isaacson JS, Scanziani M (2009) Postsynaptic mechanisms govern the differential excitation of cortical neurons by thalamic inputs. J Neurosci 29:9127-9136. CrossRef Medline

Inoue T, Imoto K (2006) Feedforward inhibitory connections from multiple thalamic cells to multiple regular-spiking cells in layer 4 of the somatosensory cortex. J Neurophysiol 96:1746-1754. CrossRef Medline

Jin J, Wang Y, Lashgari R, Swadlow HA, Alonso JM (2011) Faster thalamocortical processing for dark than light visual targets. J Neurosci 31:17471-17479. CrossRef Medline

Jones JP, Palmer LA (1987) The two-dimensional spatial structure of simple receptive fields in cat striate cortex. J Neurophysiol 58:1187-1211. Medline
Kara P, Reinagel P, Reid RC (2000) Low response variability in simultaneously recorded retinal, thalamic, and cortical neurons. Neuron 27: 635-646. CrossRef Medline

Kerlin AM, Andermann ML, Berezovskii VK, Reid RC (2010) Broadly tuned response properties of diverse inhibitory neuron subtypes in mouse visual cortex. Neuron 67:858-871. CrossRef Medline

Lee SH, Kwan AC, Zhang S, Phoumthipphavong V, Flannery JG, Masmanidis SC, Taniguchi H, Huang ZJ, Zhang F, Boyden ES, Deisseroth K, Dan Y (2012) Activation of specific interneurons improves V1 feature selectivity and visual perception. Nature 488:379-383. CrossRef Medline

Levick WR, Thibos LN (1982) Analysis of orientation bias in cat retina. J Physiol 329:243-261. Medline

Liu BH, Li P, Li YT, Sun YJ, Yanagawa Y, Obata K, Zhang LI, Tao HW (2009) Visual receptive field structure of cortical inhibitory neurons revealed by two-photon imaging guided recording. J Neurosci 29:10520-10532. CrossRef Medline

Liu BH, Li YT, Ma WP, Pan CJ, Zhang LI, Tao HW (2011) Broad inhibition sharpens orientation selectivity by expanding input dynamic range in mouse simple cells. Neuron 71:542-554. CrossRef Medline

Ma WP, Liu BH, Li YT, Huang ZJ, Zhang LI, Tao HW (2010) Visual representations by cortical somatostatin inhibitory neurons-selective but with weak and delayed responses. J Neurosci 30:14371-14379. CrossRef Medline

Mata ML, Ringach DL (2005) Spatial overlap of ON and OFF subregions and its relation to response modulation ratio in macaque primary visual cortex. J Neurophysiol 93:919-928. Medline

McLaughlin D, Shapley R, Shelley M, Wielaard DJ (2000) A neuronal network model of macaque primary visual cortex (V1): orientation selectivity and dynamics in the input layer 4Calpha. Proc Natl Acad Sci U S A 97:8087-8092. CrossRef Medline

Miller KD, Pinto DJ, Simons DJ (2001) Processing in layer 4 of the neocortical circuit: new insights from visual and somatosensory cortex. Curr Opin Neurobiol 11:488-497. CrossRef Medline

Murphy EH, Berman N (1979) The rabbit and the cat: a comparison of some features of response properties of single cells in the primary visual cortex. J Comp Neurol 188:401-427. CrossRef Medline

Murphy WJ, Eizirik E, O’Brien SJ, Madsen O, Scally M, Douady CJ, Teeling E, Ryder OA, Stanhope MJ, de Jong WW, Springer MS (2001) Resolution of the early placental mammal radiation using Bayesian phylogenetics. Science 294:2348-2351. CrossRef Medline

Naka KI, Rushton WA (1966) S-potentials from luminosity units in the retina of fish (Cyprinidae). J Physiol 185:587-599. Medline

Niell CM, Stryker MP (2008) Highly selective receptive fields in mouse visual cortex. J Neurosci 28:7520-7536. CrossRef Medline

Niell CM, Stryker MP (2010) Modulation of visual responses by behavioral state in mouse visual cortex. Neuron 65:472-479. CrossRef Medline

Nowak LG, Sanchez-Vives MV, McCormick DA (2008) Lack of orientation and direction selectivity in a subgroup of fast-spiking inhibitory interneurons: cellular and synaptic mechanisms and comparison with other electrophysiological cell types. Cereb Cortex 18:1058-1078. Medline

Ohki K, Reid RC (2007) Specificity and randomness in the visual cortex. Curr Opin Neurobiol 17:401-407. CrossRef Medline

O'Keefe LP, Levitt JB, Kiper DC, Shapley RM, Movshon JA (1998) Functional organization of owl monkey lateral geniculate nucleus and visual cortex. J Neurophysiol 80:594-609. Medline

Peirce JW (2007) The potential importance of saturating and supersaturating contrast response functions in visual cortex. J Vis 7(6):13. CrossRef Medline

Reid RC, Alonso JM (1995) Specificity of monosynaptic connections from thalamus to visual cortex. Nature 378:281-284. CrossRef Medline

Ringach DL, Hawken MJ, Shapley R (1997) Dynamics of orientation tuning in macaque primary visual cortex. Nature 387:281-284. CrossRef Medline

Ringach DL, Shapley RM, Hawken MJ (2002) Orientation selectivity in macaque V1: diversity and laminar dependence. J Neurosci 22:5639-5651. Medline

Runyan CA, Schummers J, Van Wart A, Kuhlman SJ, Wilson NR, Huang ZJ, Sur M (2010) Response features of parvalbumin-expressing interneurons suggest precise roles for subtypes of inhibition in visual cortex. Neuron 67:847-857. CrossRef Medline

Shapley RM, Xing D (2013) Local circuit inhibition in the cerebral cortex as 
the source of gain control and untuned suppression. Neural Netw 37:172181. CrossRef Medline

Skottun BC, De Valois RL, Grosof DH, Movshon JA, Albrecht DG, Bonds AB (1991) Classifying simple and complex cells on the basis of response modulation. Vision Res 31:1079-1086. Medline

Stoelzel CR, Bereshpolova Y, Gusev AG, Swadlow HA (2008) The impact of an LGNd impulse on the awake visual cortex: synaptic dynamics and the sustained/transient distinction. J Neurosci 28:5018-5028. CrossRef Medline

Stoelzel CR, Bereshpolova Y, Swadlow HA (2009) Stability of thalamocortical synaptic transmission across awake brain states. J Neurosci 29:6851-6859. CrossRef Medline

Sun QQ, Huguenard JR, Prince DA (2006) Barrel cortex microcircuits: thalamocortical feedforward inhibition in spiny stellate cells is mediated by a small number of fast-spiking interneurons. J Neurosci 26:1219-1230. CrossRef Medline

Swadlow HA (1988) Efferent neurons and suspected interneurons in binocular visual cortex of the awake rabbit: receptive fields and binocular properties. J Neurophysiol 59:1162-1187. Medline

Swadlow HA (1989) Efferent neurons and suspected interneurons in S-1 vibrissa cortex of the awake rabbit: receptive fields and axonal properties. J Neurophysiol 62:288-308. Medline

Swadlow HA (1990) Efferent neurons and suspected interneurons in S-1 forelimb representation of the awake rabbit: receptive fields and axonal properties. J Neurophysiol 63:1477-1498. Medline

Swadlow HA (1991) Efferent neurons and suspected interneurons in second somatosensory cortex of the awake rabbit: receptive fields and axonal properties. J Neurophysiol 66:1392-1409. Medline

Swadlow HA (1994) Efferent neurons and suspected interneurons in motor cortex of the awake rabbit: axonal properties, sensory receptive fields, and subthreshold synaptic inputs. J Neurophysiol 71:437-453. Medline

Swadlow HA (1995) Influence of VPM afferents on putative inhibitory interneurons in S1 of the awake rabbit: evidence from cross-correlation, microstimulation, and latencies to peripheral sensory stimulation. J Neurophysiol 73:1584-1599. Medline

Swadlow HA (2003) Fast-spike interneurons and feedforward inhibition in awake sensory neocortex. Cereb Cortex 13:25-32. CrossRef Medline
Swadlow HA, Gusev AG (2001) The impact of 'bursting' thalamic impulses at a neocortical synapse. Nat Neurosci 4:402-408. CrossRef Medline

Swadlow HA, Gusev AG (2002) Receptive-field construction in cortical inhibitory interneurons. Nat Neurosci 5:403-404. CrossRef Medline

Swadlow HA, Weyand TG (1985) Receptive-field and axonal properties of neurons in the dorsal lateral geniculate nucleus of awake unparalyzed rabbits. J Neurophysiol 54:168-183. Medline

Swadlow HA, Weyand TG (1987) Corticogeniculate neurons, corticotectal neurons, and suspected interneurons in visual cortex of awake rabbits: receptive-field properties, axonal properties, and effects of EEG arousal. J Neurophysiol 57:977-1001. Medline

Swadlow HA, Bereshpolova Y, Bezdudnaya T, Cano M, Stoelzel CR (2005) A multi-channel, implantable microdrive system for use with sharp, ultra-fine "Reitboeck" microelectrodes. J Neurophysiol 93:2959-2965. CrossRef Medline

Takahashi K (1965) Slow and fast groups of pyramidal tract cells and their respective membrane properties. J Neurophysiol 28:908-924. Medline

Tanaka K (1983) Cross-correlation analysis of geniculostriate neuronal relationships in cats. J Neurophysiol 49:1303-1318. Medline

Troyer TW, Krukowski AE, Priebe NJ, Miller KD (1998) Contrastinvariant orientation tuning in cat visual cortex: thalamocortical input tuning and correlation-based intracortical connectivity. J Neurosci 18:5908-5927. Medline

Usrey WM, Reid RC (2000) Visual physiology of the lateral geniculate nucleus in two species of new world monkey: Saimiri sciureus and Aotus trivirgatis. J Physiol 523:755-769. CrossRef Medline

Usrey WM, Reppas JB, Reid RC (1999) Specificity and strength of retinogeniculate connections. J Neurophysiol 82:3527-3540. Medline

Van Hooser SD, Heimel JA, Chung S, Nelson SB, Toth LJ (2005) Orientation selectivity without orientation maps in visual cortex of a highly visual mammal. J Neurosci 25:19-28. CrossRef Medline

Wilson NR, Runyan CA, Wang FL, Sur M (2012) Division and subtraction by distinct cortical inhibitory networks in vivo. Nature 488:343348. CrossRef Medline

Xing D, Ringach DL, Hawken MJ, Shapley RM (2011) Untuned suppression makes a major contribution to the enhancement of orientation selectivity in macaque v1. J Neurosci 31:15972-15982. CrossRef Medline 